\title{
Targeted Inhibition of P4HB Promotes Cell Sensitivity to Gemcitabine in Urothelial Carcinoma of the Bladder
}

\author{
Xiaoming Wang* \\ Yunjin Bai (D)* \\ Facai Zhang \\ Yubo Yang \\ Dechao Feng (D) \\ Ao Li \\ Zhiqiang Yang \\ Dengxiong Li (D) \\ Yin Tang \\ Xin Wei \\ Wuran Wei \\ Ping Han (D)
}

Department of Urology/Institute of Urology, West China Hospital, Sichuan University, Chengdu, Sichuan Province 61004I, People's Republic of China

*These authors contributed equally to this work
This article was published in the following Dove Press journal:
OncoTargets and Therapy

Background: Bladder cancer (BC) is a common malignancy worldwide that accounts for $3 \%$ of global cancer diagnoses. Chemotherapy resistance limits the therapeutic effect of chemotherapeutic agents in patients with BC. Prolyl 4-hydroxylase, beta polypeptide (P4HB) is an endoplasmic reticulum (ER) chaperone that is upregulated in bladder cancer tissues (The Cancer Genome Atlas, TCGA datasets). Knockdown or suppression of P4HB exerts anticancer activity and sensitizes cells to chemotherapy in various types of cancer.

Purpose: We aimed to investigate whether the inhibition of $\mathrm{P} 4 \mathrm{HB}$ enhances the anticancer efficacy of gemcitabine (GEM) in BC cells and to study the underlying molecular mechanisms.

Patients and Methods: The P4HB mRNA expression levels of $411 \mathrm{BC}$ patients from the TCGA database and P4HB expression level of eighty BC paraffin-embedded samples detected by immunohistochemistry (IHC) staining were used for clinical feature and prognostic analyses. Bioinformatics analysis was utilized for the mechanistic investigation. Highly P4HB-expressed BC cell lines (T24 and 5637) treated with P4HB inhibitor (Bacitracin, BAC) were used to study the effects of BAC on the sensitivity of BC cells to GEM and the potential mechanism. P4HB inhibition experiments were performed in highly P4HB-expressed $\mathrm{BC}$ cells, and cell viability, colony formation, cell cycle, reactive oxygen species (ROS), apoptosis and pathway proteins were assessed in T24 and 5637 cells.

Results: Western blot analysis showed that $\mathrm{P} 4 \mathrm{HB}$ expression was significantly higher in $\mathrm{BC}$ tissues than in paired normal tissues. IHC showed that patients with high P4HB expression had a poorer overall survival (OS) rate than those with low $\mathrm{P} 4 \mathrm{HB}$ expression. Furthermore, increased P4HB expression was demonstrated to be an independent prognostic marker for BC. Functionally, $\mathrm{P} 4 \mathrm{HB}$ inhibition by BAC decreased the cell proliferation ability in vitro. Moreover, BAC treatment sensitized BC cells to GEM. Molecular mechanism analysis indicated that inhibition of P4HB by BAC treatment enhanced the anticancer effects of GEM through increasing cellular ROS content and promoting cell apoptosis and PERK/eIF2 $\alpha / \mathrm{ATF} 4 / \mathrm{CHOP}$ signaling.

Conclusion: High $\mathrm{P} 4 \mathrm{HB}$ expression was significantly correlated with poor prognosis in $\mathrm{BC}$ patients. Inhibition of $\mathrm{P} 4 \mathrm{HB}$ by BAC decreased the cell proliferation ability and sensitized $\mathrm{BC}$ cells to GEM by activating apoptosis and the PERK/eIF2 $\alpha /$ ATF4/CHOP pathways.

Keywords: P4HB, ER stress, bladder cancer, gemcitabine, bacitracin

\section{Introduction}

$\mathrm{BC}$ is a common malignancy of the genitourinary system. In the United States, 81,400 new BC patients were diagnosed in 2019, and there were 17,980 BC-related deaths, ranking fourth among new male malignancies and eighth among male
Correspondence: Ping Han

Department of Urology/Institute of Urology, West China Hospital, Sichuan University, Chengdu, Sichuan Province 61004I, People's Republic of China

$\mathrm{Tel}+8618980601955$

Fax +862885582944

Email hanpingwch@163.com
OncoTargets and Therapy 2020:13 9543-9558

9543

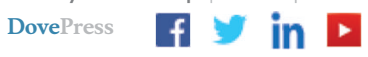

http://doi.org/| 0.21 47/OTT.S267734 
malignancy-related deaths. ${ }^{1}$ In China, approximately 80,000 people are diagnosed with $\mathrm{BC}$ each year, and approximately 32,000 people die from it. ${ }^{2}$ Therapy for $\mathrm{BC}$ is mainly dependent on surgical treatment, bladder perfusion (including BCG and chemotherapy drugs) and intravenous chemotherapy and radiotherapy. ${ }^{3}$ In recent years, immune checkpoint inhibitors have been increasingly used in the treatment of $\mathrm{BC}$, primarily in chemotherapy-resistant advanced BC. However, the clinical application of targeted therapy for BC is less satisfactory. ${ }^{3}$

GEM is a cytosine nucleoside derivative and pyrimidine analog that acts as an antitumor agent. GEM, used as a first-line chemotherapeutic agent for BC for the past two decades, has fewer side effects than other chemotherapy drugs. $^{4}$ The effect of GEM on adjuvant chemotherapy after radical cystectomy for $\mathrm{BC}$ is worthy of recognition, but its effect on advanced tumors is not ideal. Problems such as chemoresistance and patient tolerance make the first-line chemotherapy of BC limited. ${ }^{5}$ In addition, the combined antitumor effects of the targeted inhibitors bevacizumab and sorafenib as second-line drugs and GEM in BC are not ideal. $^{6}$

The growth and metabolic rates of tumor cells are high, which changes the tumor microenvironment. Hypoxic and low-nutrient tumor microenvironments can cause a large amount of unfolded proteins to accumulate in the ER cavity, thereby inducing endoplasmic reticulum stress (ERS). ${ }^{7}$ To maintain intracellular protein homeostasis, ERS activates the unfolded protein response (UPR). ERSmediated UPR can hinder tumor progression in the early stages of tumor formation, but the presence of long-term UPR can help tumor cells adapt to changes in the microenvironment and can make tumors resistant to ERSinduced apoptosis. ${ }^{8}$

Due to the high protein anabolic rate in cancer cells, enhanced protein folding ability in the ER is necessary for maintaining cell homeostasis. To meet this demand, upregulation of proteins such as protein disulfide isomerases (PDI) is usually observed. ${ }^{9}$ The PDI family is a group of enzymes in the ER responsible for the formation, breakdown and rearrangement of protein disulfide bonds, consisting of 21 members. Among the PDI family, PDIA6 is overexpressed in BC tissues and cell lines, and PDIA3 is helpful for predicting the prognosis of $\mathrm{BC} .{ }^{10,11} \mathrm{As}$ an important member of the PDI family, $\mathrm{P} 4 \mathrm{HB}$ is a multifunctional enzyme and molecular chaperone of misfolded proteins in the ER cavity and can participate in ERS and UPR. ${ }^{12} \mathrm{P} 4 \mathrm{HB}$ is generally highly expressed in a variety of cancer types, including glioma, lymphoma, renal cancer, ovarian cancer, prostate cancer and lung cancer. ${ }^{13}$ High $\mathrm{P} 4 \mathrm{HB}$ expression is associated with poor clinical prognosis of renal clear cell carcinoma and hepatocellular carcinoma. ${ }^{14,15}$ Inhibition of P4HB increases the chemosensitivity of temozolomide-resistant glioma cells and sensitizes glioma cells to radiotherapy. ${ }^{9,16}$

In our study, we determined that $\mathrm{P} 4 \mathrm{HB}$ was significantly overexpressed in BC tissues compared with adjacent normal tissues. High P4HB expression was significantly correlated with clinical features, pathological parameters, and poor prognosis. In addition, multivariate Cox proportional regression analysis showed that $\mathrm{P} 4 \mathrm{HB}$ could be a more precise and reliable prognostic factor. An in vitro study showed that the inhibition of $\mathrm{P} 4 \mathrm{HB}$ by $\mathrm{BAC}$ decreased the cell proliferation ability and sensitized $\mathrm{BC}$ cells to GEM by activating apoptosis and the PERK/ eIF2 $\alpha /$ ATF4/CHOP pathways. The data in our study suggest that $\mathrm{P} 4 \mathrm{HB}$ can serve as a potential prognostic factor and therapeutic target for $\mathrm{BC}$.

\section{Materials and Methods}

\section{Patients and Clinical Samples}

Eighty paraffin-embedded BC samples and twelve paraffin-embedded matched adjacent normal samples (normal bladder urothelium $2 \mathrm{~cm}$ adjacent to tumor tissue) of 80 patients diagnosed with BC from the Department of Pathology, West China Hospital of Sichuan University (Chengdu, China), were collected for morphological research. All patients had undergone radical cystectomy at the Department of Urology between February 2010 and December 2015. Patients who had received preoperative chemotherapy or radiotherapy were excluded. The study was conducted in accordance with the Declaration of Helsinki, and the study was performed with the permission of the Biomedical Research Ethics Committee of West China Hospital of Sichuan University (2020366). All patients signed an informed consent form for the use of their information and samples for research.

\section{TCGA Database Analysis}

P4HB mRNA expression data and corresponding clinical data were extracted from the TCGA database. Gene set enrichment analysis (GSEA) was performed to investigate the enriched biological pathways involved in high $\mathrm{P} 4 \mathrm{HB}$ expression in BC by using GSEA 4.0.2 software (a joint project of UC San Diego and Broad Institute). ${ }^{17,18}$ 


\section{Immunohistochemistry (IHC)}

Paraffin-embedded tissue sections were baked at $65^{\circ} \mathrm{C}$ for $10 \mathrm{~min}$ in an oven, deparaffinized through graded alcohol and rehydrated with xylene. The sections were preheated, submerged in boiling citric acid buffer for antigen retrieval and cooled naturally. Sections were immersed in 3\% hydrogen peroxide at room temperature for $20 \mathrm{~min}$ to block endogenous peroxidase. Then, $5-10 \%$ goat serum was utilized for nonspecific binding and incubated at $37^{\circ}$ $\mathrm{C}$ for $20 \mathrm{~min}$. The tissue sections were incubated with P4HB antibody (1: 250, ab137110, Abcam, Cambridge, UK) at $4{ }^{\circ} \mathrm{C}$ for $12 \mathrm{~h}$ in a moist chamber, followed by incubation with biotinylated goat anti-rabbit secondary antibody at room temperature for $30 \mathrm{~min}$. After washing with phosphate-buffered saline (PBS), the sections were treated with $\mathrm{SABC}$ working solution at $37{ }^{\circ} \mathrm{C}$ for $20 \mathrm{~min}$, 3,3'-diaminobenzidine (DAB) chromogenic solution and $20 \%$ hematoxylin and dehydrated. Two researchers independently evaluated the immunostaining intensity using a ZEISS microscope (AX10 Imager A2, ZEISS, Oberkochen, Germany). The P4HB expression status of immunostaining was evaluated according to staining intensity and the proportion of stained cells as follows: scoring for staining intensity of stained cells: 1 (no staining), 2 (weak staining), 3 (moderate staining), and 4 (strong staining); scoring for proportion of stained cells: $1(\geq 1 \%$ to $<25 \%), 2$ ( $\geq 25 \%$ to $<50 \%), 3(\geq 50 \%$ to $<75 \%)$ and 4 $(\geq 75 \%)$. The final score was obtained by multiplying the staining intensity score and the staining proportion score. BC patients were categorized as either the low P4HB expression group (1-8) or the high P4HB expression group (9-16).

\section{Cell Culture and Reagents}

Human BC cell lines T24, 5637, J82 and TCCSUP were purchased from the cell bank of the Committee of Culture Preservation, Chinese Academy of Sciences (Cell Resource Center, Shanghai Institute of Life Sciences, Chinese Academy of Sciences). The HUC cell line was purchased from the American Type Culture Collection (ATCC). BC cell lines T24 and 5637 were cultured in RPMI-1640 medium (HyClone, GE Health, Milwaukee, USA), BC cell lines TCCSUP and J82 were cultured in Eagle's minimum essential medium (Gibco, Carlsbad, USA), and human urothelial cells (HUCs) were maintained in Ham's F-12K (Kaighn's) medium (Gibco, Carlsbad, USA). All culture media were supplemented with 10\% FBS (Gibco, Carlsbad, USA) and
$1 \%$ antibiotics (10 units $/ \mathrm{mL}$ penicillin and $10 \mathrm{mg} / \mathrm{mL}$ streptomycin). All cells were cultured at $37{ }^{\circ} \mathrm{C}$ with $5 \% \mathrm{CO}_{2}$. Cells above $80 \%$ confluence were harvested for the experiments after culture. The P4HB-specific inhibitor BAC was purchased from Selleck Chemicals (Houston, USA). GEM was purchased from MCE Company (St. Louis, USA). T24 and 5637 cells were treated with BAC for $72 \mathrm{~h}$ and GEM for $48 \mathrm{~h}$.

\section{Cell Viability Assay and Monoclonal Cell Colony Forming Assay}

T24 and 5637 cells were seeded in 96-well plates with RPMI-1640 medium containing 10\% FBS, followed by treatment with BAC and GEM. The viability of BC cells was evaluated by the Cell Counting Kit-8 (CCK-8, Abmole, Houston, USA) assay according to the manufacturer's instructions. Cells were treated with BAC for 72 $\mathrm{h}$ alone or followed by GEM for $48 \mathrm{~h}$, and $10 \mu \mathrm{L}$ of CCK8 solution was then added to each well and incubated with the cells for $0.5-1.5 \mathrm{~h}$ at room temperature. Then, the absorbance at $450 \mathrm{~nm}$ was determined by a microplate reader (Bio-Tek, Winooski, USA). The final data were normalized to the optical density (OD) at $450 \mathrm{~nm}$ value of untreated cells. Cell viability (\%) was calculated as follows: $\frac{\mathrm{OD} \text { (treatment) }-\mathrm{OD} \text { (blank) }}{\mathrm{OD} \text { (untreated) }-\mathrm{OD} \text { (blank) }} \times 100 \%$.

For the monoclonal cell colony forming assay, T24 and 5637 cells were cultured in RPMI-1640 medium with $10 \%$ FBS at $37{ }^{\circ} \mathrm{C}$ after treatment with BAC for $72 \mathrm{~h}$ alone or followed by GEM for $48 \mathrm{~h}$, then 500 treated and untreated BC cells were seeded in 12-well plates. Untreated cells were used as the control group. After 14 days of incubation, the colonies were fixed with $4 \%$ paraformaldehyde and stained with $0.1 \%$ crystal violet for $30 \mathrm{~min}$. The colony forming efficiency was quantified by ImageProPlus 6.0 software (Media Cybernetics, Rockville, USA).

\section{Quantitative Real-Time PCR (qRT-PCR)}

Total RNA in cells was extracted using the RNeasy Mini Kit (QIAGEN, Hilden, Germany) and reverse-transcribed using the RevertAid RT Reverse Transcription Kit (Thermo Fisher Scientific, Waltham, USA) according to the manufacturer's instructions. qRT-PCR was performed using the QuantiTect SYBR Green PCR Kit (QIAGEN, Hilden, Germany). The primer sequences of GAPDH and P4HB were designed with Primer3 software (https://pri mer3.org/), and the primer sequences $\left(5^{\prime}-3^{\prime}\right)$ used were: GAPDH (accession number: NM_001256799.3): GAA 
GGT GAA GGT CGG AGT C and GAA ATC CCA TCA CCA TCT TC; P4HB (accession number: NM_000918.4): GGT GCT GCG GAA AAG CAA C and ACC TGA TCT CGG AAC CTT CTG. Relative gene expression levels were calculated using Bio-Rad CFX Manager software (Bio-Rad, Hercules, USA).

\section{Western Blot Analysis}

Western blotting was performed as described previously. ${ }^{19}$ Proteins from BC cells, tissues and normal bladder urothelial tissues were extracted in RIPA lysis buffer (Solarbio, Beijing, China) supplemented with $1 \times$ cocktail protease inhibitors (Roche, Basel, Switzerland) and $1 \times$ phosphatase inhibitors (Solarbio, Beijing, China). An enhanced BCA protein assay kit (Beyotime Biotechnology, Beijing, China) was used for quantification of protein concentration. Fifteen microliters of protein per sample was separated on $10 \%$ sodium dodecyl sulfate (SDS) polyacrylamide gels for $1.5 \mathrm{~h}$ and transferred to polyvinylidene difluoride (PVDF) membranes (MilliporeSigma, Darmstadt, Germany). The PVDF membrane was blocked by Tris-buffered saline Tween (TBST) with 5\% nonfat milk for 1-2 h. Then, the PVDF membranes were incubated with anti-P4HB (1:1000, ab137110, Abcam), anti-glyceraldehyde-3-phosphate dehydrogenase (GAPDH, 1:2000, A00191, GenScript, Nanjing, China), anti- $\beta$-Actin $(1: 2000,3700$, Cell Signaling Technology, Danvers, USA), anti- protein kinase RNA-like endoplasmic reticulum kinase (PERK,1:1000, 5683, Cell Signaling Technology), antiPhospho-PERK (p-PERK, Thr982, 1:250, PA5-40294, Invitrogen), anti- eukaryotic initiation factor $2 \alpha$ (eIF2 $\alpha$, 1:1000, 5324, Cell Signaling Technology), anti- PhosphoeIF2 $\alpha$ (p-eIF2 $\alpha$, Ser51, 1:1000, 3398, Cell Signaling Technology), anti- glucose-regulated protein $78 \mathrm{kDa}$ (GRP78/BiP, 1:1000, 3177, Cell Signaling Technology), anti- C/EBP-homologous protein (CHOP, 1:1000, 2895S, Cell Signaling Technology), anti- activating transcription factor-4 (ATF4, 1:1000, 10835-1-AP, Proteintech, Wuhan, China), anti- nuclear poly (ADP-ribose) polymerase (PARP, 1:1000, 9542, Cell Signaling Technology), anticaspase-3 (1:1000, 14220, Cell Signaling Technology), anti-caspase-7 (1:1000, 12827, Cell Signaling Technology), anti-caspase-9 (1:1000, 9508, Cell Signaling Technology), anti-cleaved caspase-3 (C-caspase-3, 1:1000, 9654, Cell Signaling Technology), anti-cleaved caspase-7 (C-caspase-7, 1:1000, 8438, Cell Signaling Technology), anti-cleaved caspase- 9
(C-caspase-9, 1:1000, 52873, Cell Signaling Technology), anti-cleaved PARP (C-PARP, 1:1000, 5625, Cell Signaling Technology), anti-Bax (1:1000, 5023, Cell Signaling Technology), anti-Bcl-2 (1:1000, 15071, Cell Signaling Technology) and anti- Phospho-Bcl-2 (p-Bcl2, Ser70, 1:1000, 2827, Cell Signaling Technology) antibodies overnight at $4{ }^{\circ} \mathrm{C}$. After washing with TBST, PVDF membranes were incubated with anti-rabbit and anti-mouse secondary antibodies (1:10,000, Zsbio, Beijing, China) for $1 \mathrm{~h}$ to confirm equal loading.

The specific protein signals were visualized using ECL reagent (Millipore), followed by exposure with a ChemiDoc ${ }^{\mathrm{TM}}$ MP Imaging System (Bio-Rad, Hercules, USA) and analysis with Image Lab Software (Bio-Rad, Hercules, USA). Equal protein loading was normalized by the density of GAPDH or $\beta$-actin.

\section{Apoptosis Analysis}

The T24 and 5637 cells were seeded in 12-well plates and treated with BAC and GEM alone or in combination. The BC cells were trypsinized briefly, washed with PBS three times and harvested by centrifugation. Apoptosis was determined by the Annexin V-FITC/PI Kit (Beijing 4A Biotech, Beijing, China). The cells were stained with annexin V-FITC and propidium iodide (PI) solution in the dark for $15 \mathrm{~min}$ at room temperature. The proportion of apoptotic cells was quantified with a flow cytometer (Beckman Coulter, Brea, USA).

\section{Cell Cycle Analysis}

T24 and 5637 cells were seeded in 6-well plates and treated with BAC or GEM alone or in combination. The cells in log phase were harvested by trypsinization and washed with PBS. The cells were fixed in $75 \%$ methanol overnight at $4{ }^{\circ} \mathrm{C}$. PI solution and DNase-free RNase A from a cell cycle and apoptosis analysis kit (Beijing 4A Biotech, Beijing, China) were used to stain the cells for $30 \mathrm{~min}$ at room temperature in the dark. A total of 10,000 cells per sample were analyzed by a flow cytometer (Beckman Coulter, Brea, USA).

\section{ROS Detection}

ROS content in cells was determined with an ROS Assay Kit (Beyotime Biotechnology, Beijing, China). T24 and 5637 cells treated with drugs were incubated with $10 \mu \mathrm{M}$ DCFH-DA solution for $30 \mathrm{~min}$ at $37^{\circ} \mathrm{C}$ in the dark. After incubation, the cells were harvested by trypsinization and washed with PBS. The fluorescence intensity was detected by flow cytometry 
(Beckman Coulter, Brea, USA), and the results were analyzed with FlowJo 10.0 (BD, Franklin Lakes, USA) software.

\section{PDI Activity Detection}

T24 and 5637 cells were seeded in 96-well plates. After treatment by BAC and GEM, the PDI inhibitor screening kit (BioVision, Milpitas, USA) was used to detect the PDI activity of the cell line according to the instructions. The fluorescence $(E x / E m=440 / 490 \mathrm{~nm})$ was measured by a microplate reader at $5 \mathrm{~min}$ and $30 \mathrm{~min}\left(\mathrm{FLU}_{5}\right.$ and $\left.\mathrm{FLU}_{30}\right)$ of incubation at $37^{\circ} \mathrm{C}$. After subtracting the background for all samples, the slopes of each sample (Slop-S) were calculated as follows: Slop $-\mathrm{S}=\frac{\mathrm{FLU}_{30}-\mathrm{FLU}_{5}}{30-5(\mathrm{~min})}$, and no drug-treated cells were used as the control group. The slope for the enzyme control (EC, no inhibitor) group (Slop-E) was calculated in the same way. PDI activity (\%) was calculated as follows: PDIactivity $(\%)=\frac{\text { Slop-S }}{\text { Slop }-\mathrm{E}} \times 100 \%$.

\section{Statistical Analysis}

GraphPad Prism 8.0 (GraphPad Software, La Jolla, USA), SPSS 25.0 (IBM Corporation, Armonk, USA) and R 3.6.2 (www.r-project.org) were used for the statistical analysis of all experimental data. The clinical or test measurement data are expressed as the mean \pm standard deviation (SD). In the statistical analysis of continuous variables between the two groups, paired or unpaired $t$ tests were used. One-way ANOVA was used to perform statistical analysis of three or more continuous variables. The relationship between P4HB expression and clinicopathological features was analyzed by binary logistic regression and chi-square tests. Survival analysis was performed using Kaplan-Meier and Log rank tests. Univariate and multivariate Cox regression analyses were also performed to compare variables. $p<$ 0.05 indicated statistical significance, and all results were defined as ${ }^{*} p<0.05 ;{ }^{* *} p<0.01 ;{ }^{* * *} p<0.001$; $* * * * p<0.0001$; or not significant (ns).

\section{Results}

\section{P4HB is Highly Expressed in BC}

To determine the tumorigenic profiles of $\mathrm{P} 4 \mathrm{HB}$ in $\mathrm{BC}$, we mined the data on P4HB mRNA expression in $\mathrm{BC}$ tissues from the TCGA database and found that $\mathrm{P} 4 \mathrm{HB}$ mRNA levels were higher in the $411 \mathrm{BC}$ tissues than in the 19 matched normal tissues (Figure 1A). The protein level of P4HB was also determined by IHC detection of
80 paraffin-embedded $\mathrm{BC}$ samples and 12 randomly selected normal tissues (Figure 1B); the results showed that $\mathrm{P} 4 \mathrm{HB}$ protein expression was upregulated in $\mathrm{BC}$ tissues compared with adjacent normal tissues (Figure 1C). Moreover, P4HB protein and mRNA expression levels were also measured in 4 BC cell lines (T24, 5637, TCCSUP and J82) and the normal urothelium cell line HUC, and the results revealed that P4HB expression in T24 and 5637 cells was clearly higher than that in HUC cells (Figure 1D and E). In the subgroup analysis of the TCGA dataset, the high P4HB expression was also associated with higher tumor grade, age and stage but not with sex (Figure S1).

In the logistic regression of the TCGA database, high expression of $\mathrm{P} 4 \mathrm{HB}$ was correlated with high tumor grade, stage (IV vs II), pathological $\mathrm{N}$ stage and age (Table 1). The baseline data of $80 \mathrm{BC}$ patients are presented in Table 2, and the chi-square test indicated that high P4HB expression had a significant correlation with sex and stage.

\section{Overexpression of $\mathrm{P} 4 \mathrm{HB}$ is Correlated with Poor Survival in BC}

Kaplan-Meier survival analysis indicated that high P4HB expression was significantly correlated with worse OS in both BC patients from the TCGA database and the 80 patients in our database $(p<0.05$, Figure $2 \mathrm{~A}$ and B).

Cox regression analysis was performed on patients from both the TCGA database and the 80-BC patient database. Univariate Cox regression analyses revealed that poor OS outcome was significantly associated with high $\mathrm{P} 4 \mathrm{HB}$ expression, age, stage, pathological $\mathrm{N}$ stage and pathological $M$ stage in the TCGA database (Table 3). Poor OS was notably correlated with high P4HB expression, stage (II, III, IV), tumor grade and smoking in the 80-BC patient database (Table 4). Moreover, multivariate Cox regression analysis demonstrated that $\mathrm{P} 4 \mathrm{HB}$ and age were independent prognostic factors in the TCGA database analysis. High P4HB expression, stage (III and IV), and smoking were independent prognostic factors for OS in the 80-BC patient database. A nomogram was generated based on multivariate Cox regression analysis in the TCGA database (Figure 2C). 

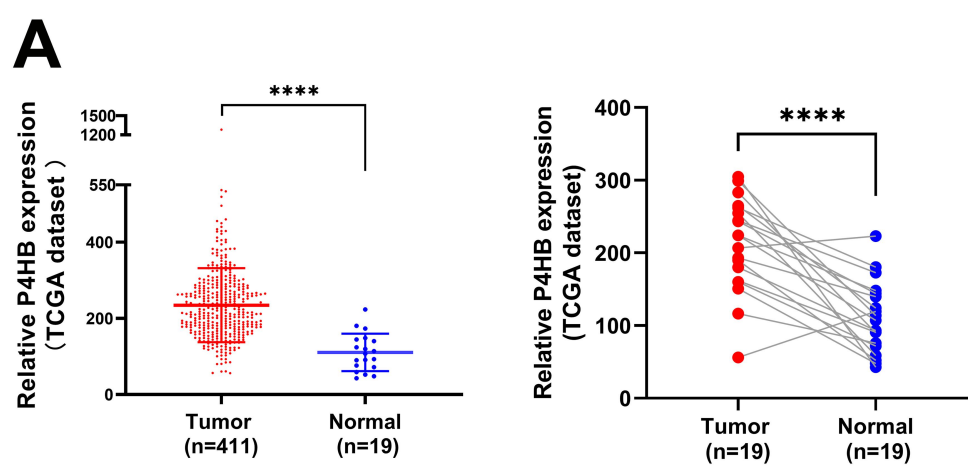

B

C
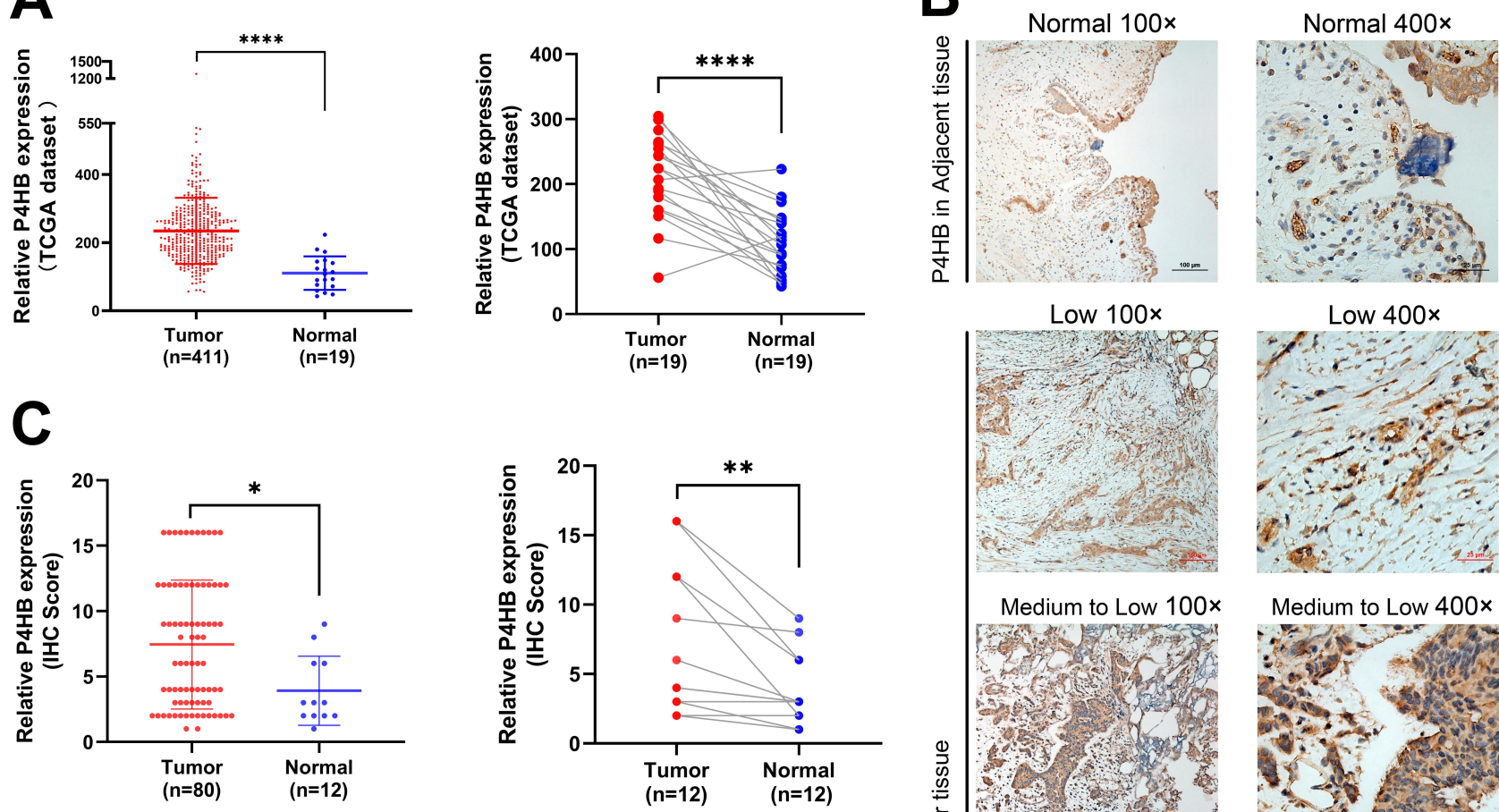

Low $100 \times$

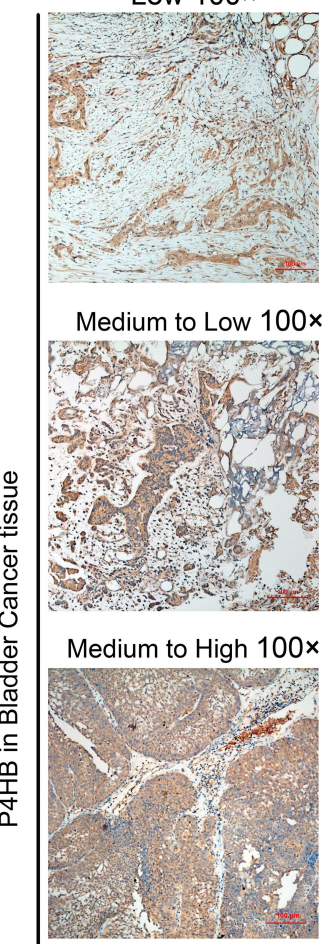

Low 400x

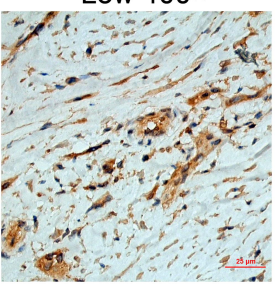

Medium to Low 400x

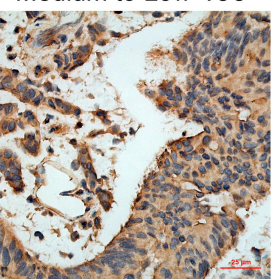

D

\section{P4HB}

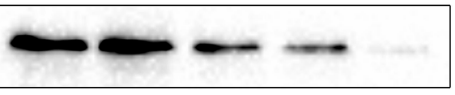

GAPDH
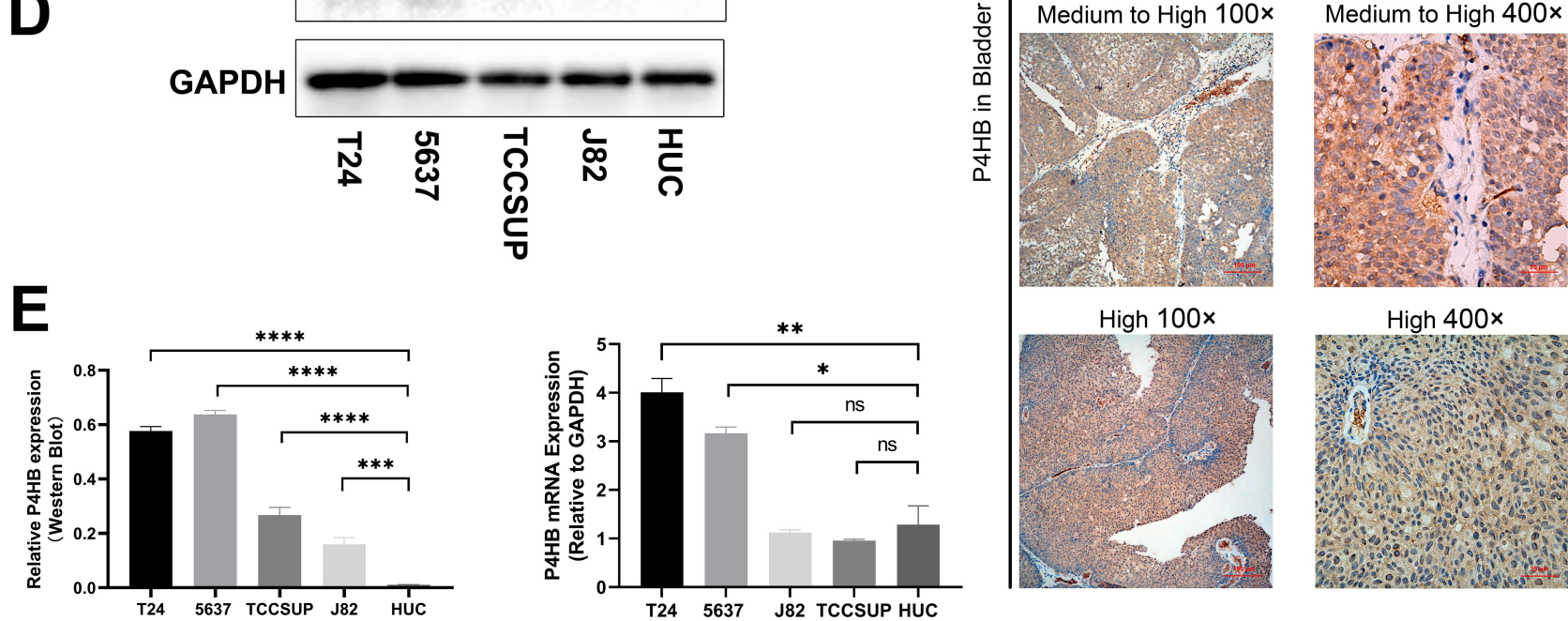

High 400x

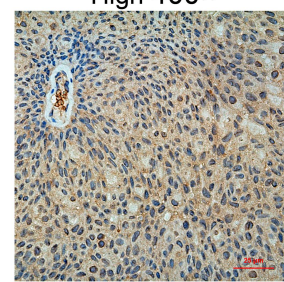

Figure I Expression of P4HB in BC samples. (A) Upregulated P4HB mRNA expression in 4II BC and 19 matched normal bladder tissues from the TCGA database. (B) Representative IHC images of $B C$ tissues and adjacent normal tissues. (C) P4HB protein was highly expressed in BC tissues compared with matched normal bladder tissues (data from 80 BC patients). (D and E) Western blotting and q-RT PCR analysis of P4HB expression in 4 BC and HUC cell lines. Values are expressed as the mean \pm SD. Statistical significance was analyzed by Student's $t$ test and indicated by ns, $p>0.05 ; * p<0.05 ; * * p<0.01 ; * * *<0.001$ and $* * * * p<0.0001$.

\section{P4HB May Influence Nutrient Metabolism in $B C$}

To further explore the biological function of $\mathrm{P} 4 \mathrm{HB}$ in $\mathrm{BC}$, we conducted GSEA using the TCGA database. Gene sets enriched in the high P4HB expression phenotype included amino sugar and nucleotide sugar metabolism, glycan biosynthesis, glycosphingolipid biosynthesis, galactose metabolism, other glycan degradation, steroid biosynthesis and biosynthesis of unsaturated fatty acids (Figure S2 and Table S1).

\section{Suppression of P4HB Inhibits BC Cell} Proliferation and Colony Formation and

\section{Sensitizes BC Cells to GEM in vitro}

P4HB inhibition experiments applied in BC cells with high P4HB expression (T24 and 5637 cells). To investigate the 
Table I Relationship Between P4HB mRNA Overexpression and Clinicopathologic Parameters in BC Tissues from the TCGA Database

\begin{tabular}{|l|l|l|l|l|l|}
\hline Clinicopathological Characteristics & Sample Size & Odd Ratio & \multicolumn{2}{l|}{$\mathbf{9 5 \%} \mathbf{C l}$} & \multicolumn{2}{l|}{-value } \\
\hline Grade (High vs Low) & 402 & 6.492 & 1.811 & 22.400 & 0.003 \\
Stage (IV vs II) & 263 & 2.06 & 1.26 & 3.667 & 0.004 \\
Stage (IV vs III) & 272 & 1.311 & 0.799 & 2.149 & 0.284 \\
PM (Positive vs Negative) & 205 & 1.786 & 0.507 & 6.3 & 0.367 \\
PN (Positive vs Negative) & 364 & 1.926 & 1.245 & 2.982 & 0.003 \\
Sex (Male vs Female) & 405 & 1.033 & 0.662 & 1.611 & 0.886 \\
Age (Continuous) & 405 & 1.02 & 1.001 & 1.039 & 0.04 \\
\hline
\end{tabular}

Note: $p$-values were calculated by binary logistic regression analysis.

Abbreviations: $\mathrm{Cl}$, confidence interval; pM, pathologic distant metastases; pN, pathologic lymph node metastases.

biological role of $\mathrm{P} 4 \mathrm{HB}$ in $\mathrm{BC}$, a CCK-8 assay was utilized to detect the cell viability of T24 and 5637 cells treated with BAC and GEM alone or in combination. Both BAC and GEM inhibited BC cells in a dosedependent manner (Figure $3 \mathrm{~A}$ and $\mathrm{B}$ ). Above all, combined management with BAC could enhance the ability of GEM to suppress the proliferation of BC cells (Figure 3C). Colony formation assays demonstrated that the combination of BAC and GEM achieved the best inhibitory effect on colony formation ability in both T24 and 5637 cells (Figure 3D).

\section{Inhibition of P4HB Increases ROS Contents and Regulates the Cell Cycle Under GEM Treatment}

Intracellular ROS content determined by cytometry indicated that BAC or GEM alone slightly increased ROS levels in T24 cells, and the highest level of ROS existed in the combined group. The same alteration of ROS was also observed in 5637 cells; however, this alteration was not statistically significant (Figure 4A).

Similarly, we detected the cell cycle distribution in T24 and 5637 cells after the same treatment (Figure 4B). As an S phase-specific drug, GEM significantly induced S phase arrest in T24 and 5637 cells $(p<0.05)$. The proportion of T24 and 5637 cells in the G2/M phase increased in the BAC group compared with the control group $(p<0.05)$. Cell cycle detection of T24 and 5637 cells in the combined group showed that the population of cells in $\mathrm{G} 0 / \mathrm{G} 1$ phase increased compared with that in the control group $(p<0.05)$; the percentage of cells in $\mathrm{G} 2 / \mathrm{M}$ phase was $0 \%$, and obvious change of $\mathrm{S}$ phase only occurred in T24 cells.

\section{P4HB Inhibition Leads to ERS and Apoptosis in BC Cells}

Therefore, we attempted to determine whether BAC triggered ERS by inhibiting P4HB in BC cells. ERS pathway proteins, including GRP78/BiP, PERK, p-PERK, eIF2 $\alpha$, p-eIF2 $\alpha$ and ATF4, were assessed by Western blot analysis in BACtreated BC cells. A dose-dependent increase in PERK, p-PERK and p-eIF2 $\alpha$ was recorded in T24 and 5637 cells. Peak ATF4 levels were found in the $1000 \mu \mathrm{M}$ BAC group of 5637 cells. The eIF2 $\alpha$ level was consistent in all BAC-treated groups. Moreover, BAC at the highest dose decreased the levels of GRP78/BiP in T24 and 5637 cells. The above findings thus suggested that inhibition of P4HB activated the PERK/eIF2 $\alpha /$ ATF4 signaling pathway (Figure 5A).

To further explore the potential role of $\mathrm{P} 4 \mathrm{HB}$ in $\mathrm{BC}$, apoptosis in BC cells was detected by flow cytometry technology. The percentage of total apoptotic cells increased in a dose-dependent manner in T24 and 5637 cells treated with $\mathrm{BAC}(0,250,750,1000 \mu \mathrm{M}$; Figure 5B).

\section{PDI Activity is Inhibited by BAC and GEM in BC Cells}

Under the same conditions, BAC induced an obvious decrease in PDI activity in both T24 and 5637 cells, and GEM decreased PDI activity in both cell lines, with statistical significance in 5637 cells; a slight synergistic effect was observed in the combined group (Figure 6A).

\section{P4HB Inhibitor Sensitizes BC Cells to GEM-Mediated Cell Apoptosis via the PERK/elF2 $\alpha / A T F 4 / C H O P$ Pathway}

To further elucidate the effect of $\mathrm{P} 4 \mathrm{HB}$ inhibition on chemosensitivity to GEM in $\mathrm{BC}$ cells, hallmarks 
Table 2 Correlations Between P4HB Protein Overexpression and Clinicopathologic Parameters in BC Tissues from $80 \mathrm{BC}$ Patients

\begin{tabular}{|c|c|c|c|}
\hline $\begin{array}{l}\text { Clinicopathological } \\
\text { Characteristics }\end{array}$ & $\begin{array}{l}\text { P4HB High } \\
\text { Expression }\end{array}$ & $x^{2}$ & $p$-value \\
\hline $\begin{array}{l}\text { Age }(62.04 \pm 10.55) \\
\quad \leq 65 \\
>65\end{array}$ & $\begin{array}{l}43.75 \%(2 \mathrm{I} / 48) \\
43.75 \%(14 / 32)\end{array}$ & 0.000 & 1.000 \\
\hline $\begin{array}{l}\text { Sex } \\
\qquad \text { Male } \\
\text { Female }\end{array}$ & $\begin{array}{l}47.29 \%(35 / 74) \\
0 \%(0 / 6)\end{array}$ & 5.045 & 0.033 \\
\hline $\begin{array}{l}\text { Grade } \\
\text { High } \\
\text { Low }\end{array}$ & $\begin{array}{l}46.42 \%(26 / 56) \\
37.5 \%(9 / 24)\end{array}$ & 0.544 & 0.623 \\
\hline $\begin{array}{l}\text { Stage } \\
\text { I } \\
\text { II } \\
\text { III } \\
\text { IV }\end{array}$ & $\begin{array}{l}28.13 \%(9 / 32) \\
57.14 \%(12 / 21) \\
83.33 \%(10 / 12) \\
26.67 \%(4 / 15)\end{array}$ & 14.124 & 0.003 \\
\hline $\begin{array}{l}\mathrm{PT} \\
\text { TI } \\
\text { T2 } \\
\text { T3 } \\
\text { T4 }\end{array}$ & $\begin{array}{l}27.27 \%(9 / 33) \\
56.00 \%(14 / 25) \\
56.25 \%(9 / 16) \\
50 \%(3 / 6)\end{array}$ & 6.276 & 0.099 \\
\hline $\begin{array}{l}\mathrm{pN} \\
\mathrm{N} 0 \\
\mathrm{~N} 1 \\
\mathrm{~N} 2\end{array}$ & $\begin{array}{l}42.86 \%(27 / 63) \\
63.64 \%(7 / I I) \\
16.67 \%(1 / 6)\end{array}$ & 3.576 & 0.167 \\
\hline $\begin{array}{l}\text { pM } \\
\text { Mo } \\
\text { MI }\end{array}$ & $\begin{array}{l}43.42 \%(33 / 76) \\
50 \%(2 / 4)\end{array}$ & 0.067 & 1.000 \\
\hline $\begin{array}{l}\text { Recurrence } \\
\text { Yes } \\
\text { No }\end{array}$ & $\begin{array}{l}43.48 \%(10 / 23) \\
43.86 \%(25 / 57)\end{array}$ & 0.01 & 1.000 \\
\hline $\begin{array}{c}\text { Smoking } \\
\text { Yes } \\
\text { No }\end{array}$ & $\begin{array}{l}\text { Smoking } \\
45.83 \%(22 / 48) \\
40.63 \%(13 / 32)\end{array}$ & 0.212 & 0.818 \\
\hline
\end{tabular}

Note: $p$-values were calculated by the Pearson $x^{2}$ test.

Abbreviations: $\mathrm{Cl}$, confidence interval; $\mathrm{pT}$, pathologic $\mathrm{T}$ stage; $\mathrm{pN}$, pathologic lymph node metastases; pM, pathologic distant metastases.

(GRP78/BiP and PERK/eIF2 $\alpha /$ ATF4/CHOP pathway) of ERS were determined in T24 and 5637 cells treated with BAC and GEM by Western blot analysis. GEM potentiated ERS (protein levels of p-PERK, p-eIF2 $\alpha$, ATF4 and $\mathrm{CHOP}$ ) in $\mathrm{BC}$ cells. Interestingly, peak protein levels of p-PERK, p-eIF2 $\alpha$, ATF4 and CHOP appeared in the BAC and GEM combined group compared with the groups treated with each drug alone, indicating that $\mathrm{BAC}$ potentiated the ERS-inducing effect of GEM in T24 and in 5637 cells (Figure 6B). GRP78/BiP and eIF2 $\alpha$ were upregulated in all drug intervention groups, and PERK expression was decreased in the GEM and combined groups (Figure 6B).

According to the results from flow cytometry analysis (Figure 6C), the percentage of total apoptotic cells treated with BAC or GEM alone was higher than that in the control group. When treated with the combined intervention, the effect was augmented. Our data suggest that P4HB suppression-induced apoptosis in T24 and 5637 cells notably contributed to cell death caused by GEM treatment.

The Bcl-2 family is located upstream of the apoptosis signaling pathway, including molecules that inhibit apoptosis or promote apoptosis. The ratio of $\mathrm{Bcl}-2 / \mathrm{Bax}$ can be used as a criterion for judging the level of apoptosis. After BAC and GEM monotherapy and combined intervention, the protein expression level of Bax in T24 and 5637 cells was significantly increased in the GEM and combination groups, and the Bax expression level in the combination group was higher than that in the other groups; the Bcl-2 expression level in T24 cells decreased in the GEM and combination group, but there was no obvious change in the level in 5637 cells, and the phosphorylated Bcl-2 (p-Bcl-2) level increased in the three experimental groups of two kinds of cells. In the caspase family, the expression levels of C-caspase-3, C-caspase-9 and C-PARP were significantly increased in the GEM group and combination group of the two cells. The expression of C-caspase- 3 increased dramatically in the combination group in 5637 cells. The expression levels of C-caspase-7 increased slightly in the three treated groups of the two cell types. The expression levels of caspase-3, caspase-7, caspase- 9 and PARP were reduced in all experimental groups, most notably in the combination group. C-caspase- 3 has catalytic activity and can cleave PARP, which separates the catalytic region where PARP binds to DNA, resulting in increased endonuclease activity and DNA cleavage, eventually leading to cell death (Figure 6D).

\section{Discussion}

P4HB, also known as PDIA1, PDI or CLCRP1, is a vital disulfide isomerase, redox enzyme and chaperone in the ER and is regarded as a prognostic factor related to the genesis and progression of multiple carcinomas. ${ }^{20-22}$ However, the correlation between $\mathrm{P} 4 \mathrm{HB}$ and $\mathrm{BC}$ remains unclear. Our study demonstrated for the first time that the 

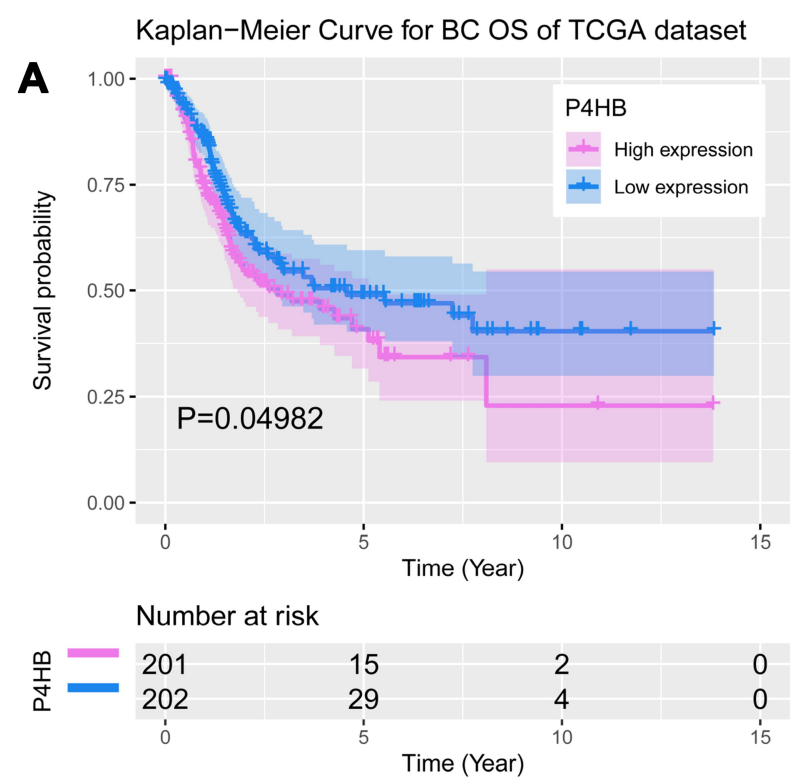

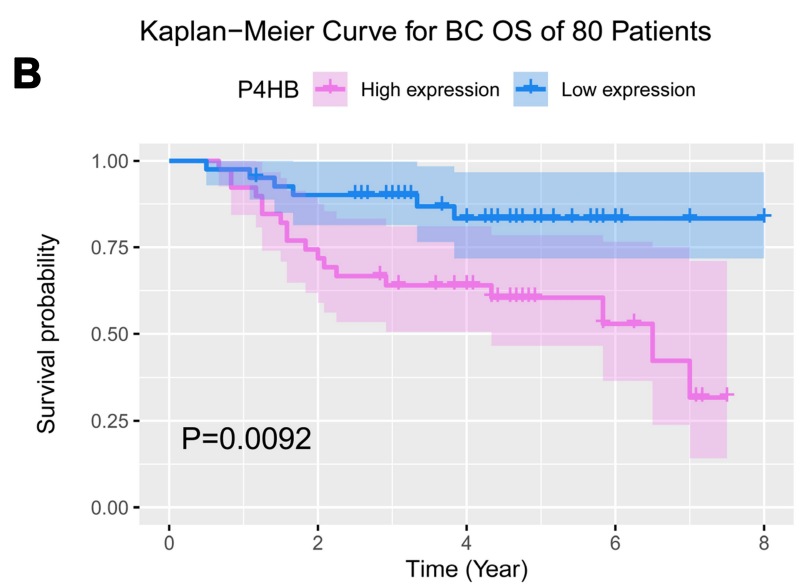

Number at risk

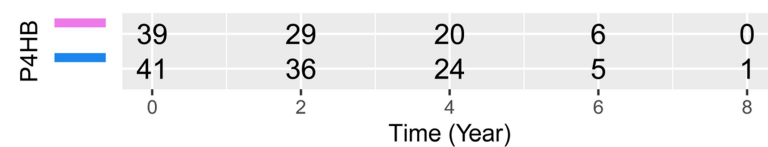

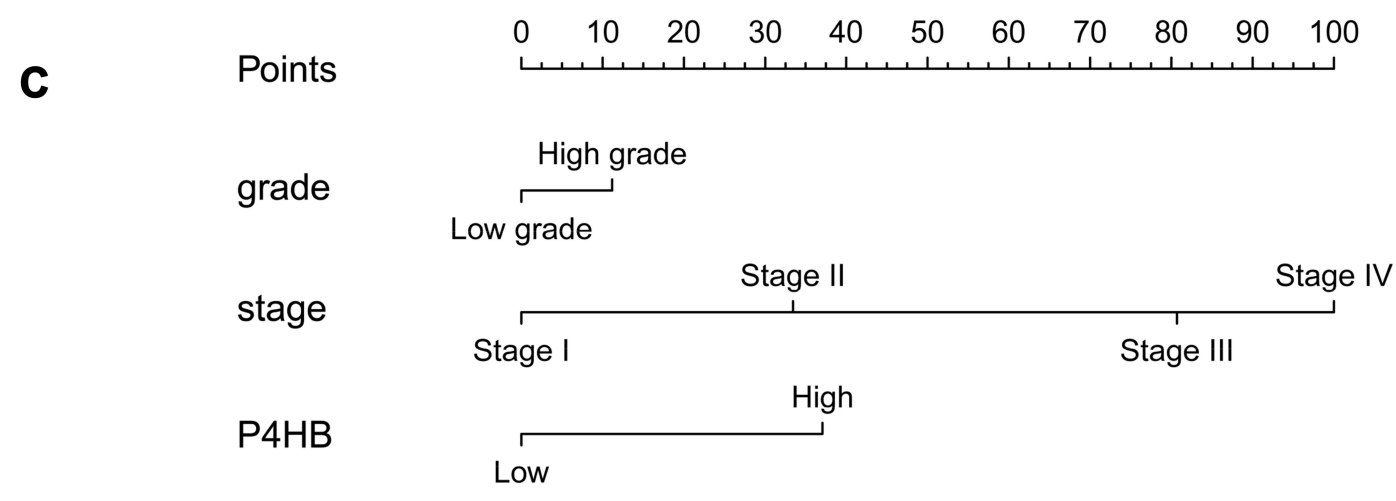

Total Points

$0 \begin{array}{lllllll}10 & & 100 & 120 & 140 & 160\end{array}$

1-year survival

\begin{tabular}{llll}
\hline 0.99 & 0.96 & 0.9 & 0.8
\end{tabular}

3-year survival

$\begin{array}{llllll}0.99 & 0.96 & 0.9 & 0.8 & 0.6 & 0.3\end{array}$

5-year survival

$\begin{array}{lllllll}0.99 & 0.96 & 0.9 & 0.8 & 0.6 & 0.3 & 0.05\end{array}$

Figure 2 Kaplan-Meier analysis of OS in BC patients. (A) OS analysis of P4HB mRNA expression in 4 II BC patients from the TCGA database (Log rank test: $p<0.05)$. (B) OS analysis of P4HB protein expression in 80 BC patients (Log rank test: $p<0.01$ ). (C) Nomogram based on tumor grade, stage and P4HB expression concerning the I-, 3-, and 5-year survival probability of BC patients from the TCGA database.

expression of $\mathrm{P} 4 \mathrm{HB}$ was elevated in $\mathrm{BC}$ tissues from 80 patients and $\mathrm{BC}$ cell lines, which was consistent with results from the TCGA database analysis. In previously published studies, P4HB and PDIA3 played an important role in diffuse glioma progression and therapeutic outcomes, ${ }^{23}$ and the PDI family is associated with the survival and tumor progression of glioma. ${ }^{22}$ Moreover, recent research revealed that high $\mathrm{P} 4 \mathrm{HB}$ expression is correlated with poor prognosis in hepatocellular carcinoma $^{15}$ and could be a potential prognostic biomarker in gastric cancer. ${ }^{20} \mathrm{P} 4 \mathrm{HB}$ is highly expressed in renal clear cell carcinoma (ccRCC) and positively correlated with pathological grade, stage and poor prognosis; it has been verified as an independent risk factor by multifactor Cox 
Table 3 Univariate and Multivariate Analysis of OS in 4II BC Patients from TCGA Database

\begin{tabular}{|c|c|c|c|c|c|c|c|c|}
\hline \multirow{3}{*}{$\begin{array}{l}\text { Parameter } \\
\mathrm{P} 4 \mathrm{HB}\end{array}$} & \multicolumn{4}{|c|}{ Univariate Analysis } & \multicolumn{4}{|c|}{ Multivariate Analysis } \\
\hline & \multirow{2}{*}{$\begin{array}{l}\text { HR } \\
2.062\end{array}$} & \multicolumn{2}{|c|}{$95 \% \mathrm{Cl}$} & \multirow{2}{*}{$\begin{array}{l}p \text {-value } \\
<0.001\end{array}$} & \multirow{2}{*}{$\begin{array}{l}\text { HR } \\
1.7 \mid\end{array}$} & \multicolumn{2}{|c|}{$95 \% \mathrm{Cl}$} & \multirow{2}{*}{$\begin{array}{l}p \text {-value } \\
0.003\end{array}$} \\
\hline & & 1.452 & 2.923 & & & 1.197 & 2.443 & \\
\hline Age & 1.04 & 1.022 & 1.06 & $<0.001$ & 1.04 & 1.021 & 1.06 & $<0.001$ \\
\hline Sex & 0.881 & 0.604 & 1.284 & 0.509 & 0.821 & 0.559 & 1.206 & 0.316 \\
\hline Stage & 1.946 & 1.523 & 2.488 & $<0.001$ & 1.423 & 0.909 & 2.228 & 0.123 \\
\hline pT & 1.667 & 1.288 & 2.158 & $<0.001$ & 1.334 & 0.978 & 1.82 & 0.068 \\
\hline $\mathrm{pN}$ & 1.583 & 1.327 & 1.889 & $<0.001$ & 1.151 & $0.84 I$ & 1.574 & 0.379 \\
\hline
\end{tabular}

Abbreviations: $\mathrm{HR}$, hazard ratio; $\mathrm{Cl}$, confidence interval; $\mathrm{pT}$, pathologic $\mathrm{T}$ stage; $\mathrm{pN}$, lymph node metastases.

Table 4 Univariate and Multivariate Analysis of OS in 80 BC Patients

\begin{tabular}{|c|c|c|c|c|c|c|c|c|}
\hline \multirow{3}{*}{$\begin{array}{l}\text { Parameter } \\
\text { P4HB }\end{array}$} & \multicolumn{4}{|c|}{ Univariate Analysis } & \multicolumn{4}{|c|}{ Multivariate Analysis } \\
\hline & \multirow{2}{*}{$\begin{array}{l}\text { HR } \\
2.260\end{array}$} & \multicolumn{2}{|c|}{$95 \% \mathrm{Cl}$} & \multirow{2}{*}{$\frac{p \text {-value }}{0.004}$} & \multirow{2}{*}{$\begin{array}{l}\text { HR } \\
2.281\end{array}$} & \multicolumn{2}{|c|}{$95 \% \mathrm{Cl}$} & \multirow{2}{*}{$\frac{p \text {-value }}{0.013}$} \\
\hline & & 1.303 & 3.92 & & & 1.189 & 4.376 & \\
\hline Stage II & 6.390 & 1.172 & $34.84 I$ & 0.032 & 4.240 & 0.585 & 30.707 & 0.153 \\
\hline Stage III & 40.910 & 6.636 & 252.215 & $<0.001$ & 21.084 & 2.674 & 166.272 & 0.003 \\
\hline Stage IV & 39.502 & 6.489 & 240.462 & $<0.001$ & 52.384 & 6.168 & 444.838 & $<0.001$ \\
\hline Grade & 0.187 & 0.044 & 0.794 & 0.023 & 0.999 & 0.169 & 5.921 & 0.999 \\
\hline Age & 1.013 & 0.974 & 1.054 & 0.525 & 0.999 & 0.947 & 1.053 & 0.963 \\
\hline Smoking & 2.887 & 1.077 & 7.74 & 0.035 & 2.887 & 1.077 & 7.741 & 0.035 \\
\hline Recurrence & 0.45 & 0.2 & 1.020 & 0.057 & 0.674 & 0.275 & 1.648 & 0.387 \\
\hline
\end{tabular}

Abbreviations: $\mathrm{HR}$, hazard ratio; $\mathrm{Cl}$, confidence interval.

regression in ccRCC. ${ }^{14}$ In addition, logistic regression and chi-square tests were conducted in $80 \mathrm{BC}$ patients and TCGA database patients and indicated that P4HB overexpression in tissues is strongly associated with the clinicopathological characteristics of BC. Most importantly, BC patients with higher $\mathrm{P} 4 \mathrm{HB}$ expression had a worse prognosis than those with lower expression. Cox regression analysis identified $\mathrm{P} 4 \mathrm{HB}$ as an independent factor for poor prognosis in BC. Above all, the clinical data suggested that $\mathrm{P} 4 \mathrm{HB}$ is a potential prognostic biomarker requiring further validation and may play important roles in $\mathrm{BC}$ progression.

P4HB plays a key role in maintaining and regulating intracellular protein homeostasis and has become a new target in the field of cancer therapy research. The oncogenic roles of $\mathrm{P} 4 \mathrm{HB}$ and its biological function in $\mathrm{BC}$ remain elusive. Pharmacological inhibition of $\mathrm{P} 4 \mathrm{HB}$ suppressed tumor proliferation in vivo and induced cell apoptosis in vitro in $\mathrm{HCC}^{24} \mathrm{P} 4 \mathrm{HB}$ plays a critical role in carcinogenesis in glioma, and overexpression of P4HB leads to proliferation, invasion, migration and angiogenesis in vivo and increases tumor growth through the mitogen-activated protein kinase (MAPK) signaling pathway in vitro. ${ }^{25}$ Genetic and pharmacological inhibition of P4HB induces ERS, and early-stage ERS has protective effects on cells and promotes malignancy of tumor cells, making tumors resistant to apoptosis induced by ERS. ${ }^{8}$ However, persistent ERS induces apoptosis to prevent tumor cells from proliferating. ${ }^{26}$ Usually, apoptosis is activated by the mitochondrial pathway death receptor pathway and ERS. ${ }^{27}$ ERS caused by chemotherapeutic agents stimulates the apoptosis signaling pathway through the PERK/eIF2 $\alpha / \mathrm{ATF} 4 / \mathrm{CHOP}$ signaling axis. CHOP increases the protein expression of $\mathrm{Bax}$ and decreases the protein level of Bcl2, activating the caspase signaling pathway and eventually inducing apoptosis. ${ }^{28,29}$ P4HB was functionally inhibited with BAC, a peptide antibiotic proven to be able to inhibit $\mathrm{P} 4 \mathrm{HB}$ and cell wall biosynthesis, to investigate the biological roles of $\mathrm{P} 4 \mathrm{HB}$ in BC. ${ }^{30}$ To further clarify the specific role of ERS in BAC-induced cellular apoptosis, we performed P4HB inhibition experiments in highly P4HB-expressed T24 and 5637 cells, and we detected the cell proliferation, apoptosis, ERS and caspase pathway proteins in $\mathrm{BC}$ cells in the BAC treatment group compared 
A

T24

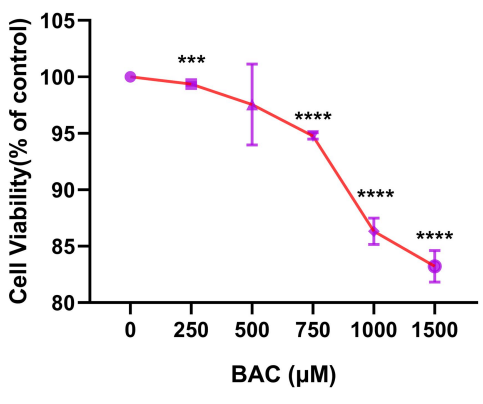

5637

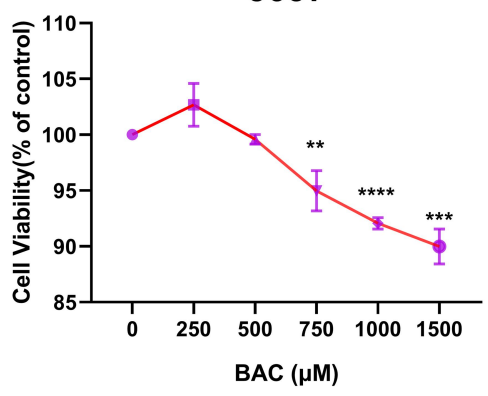

D
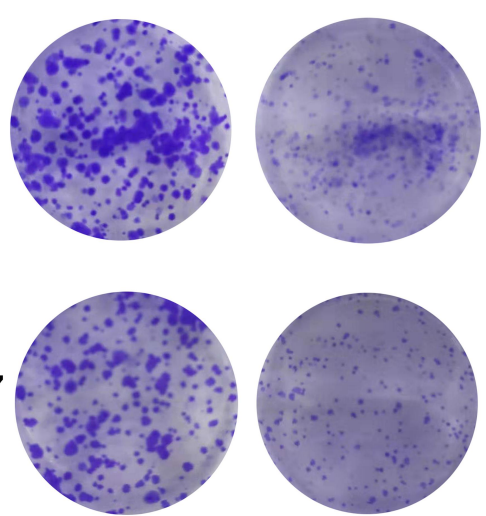

Control

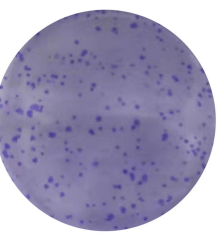

BAC

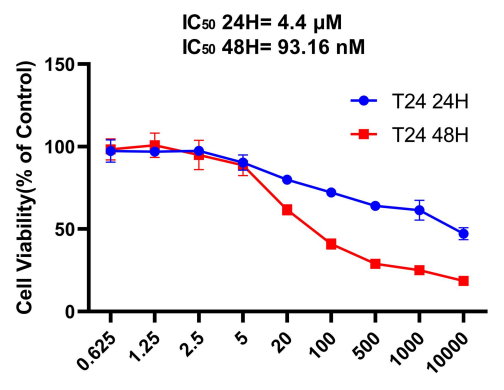

GEM (nM)

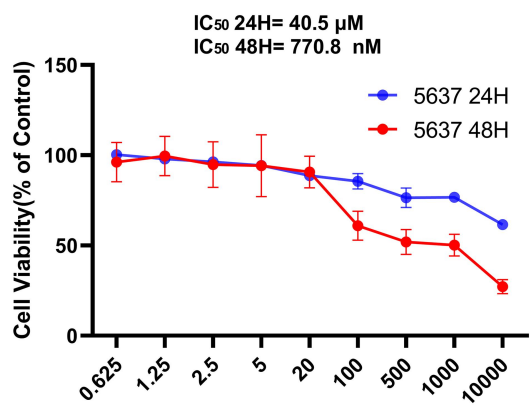

GEM (nM)
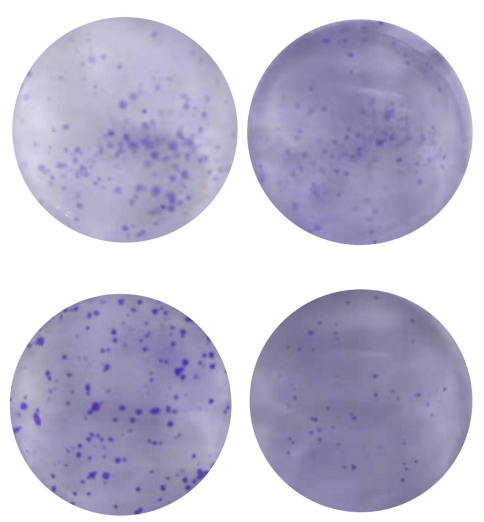

GEM

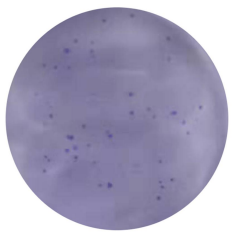

BAC+GEM
C
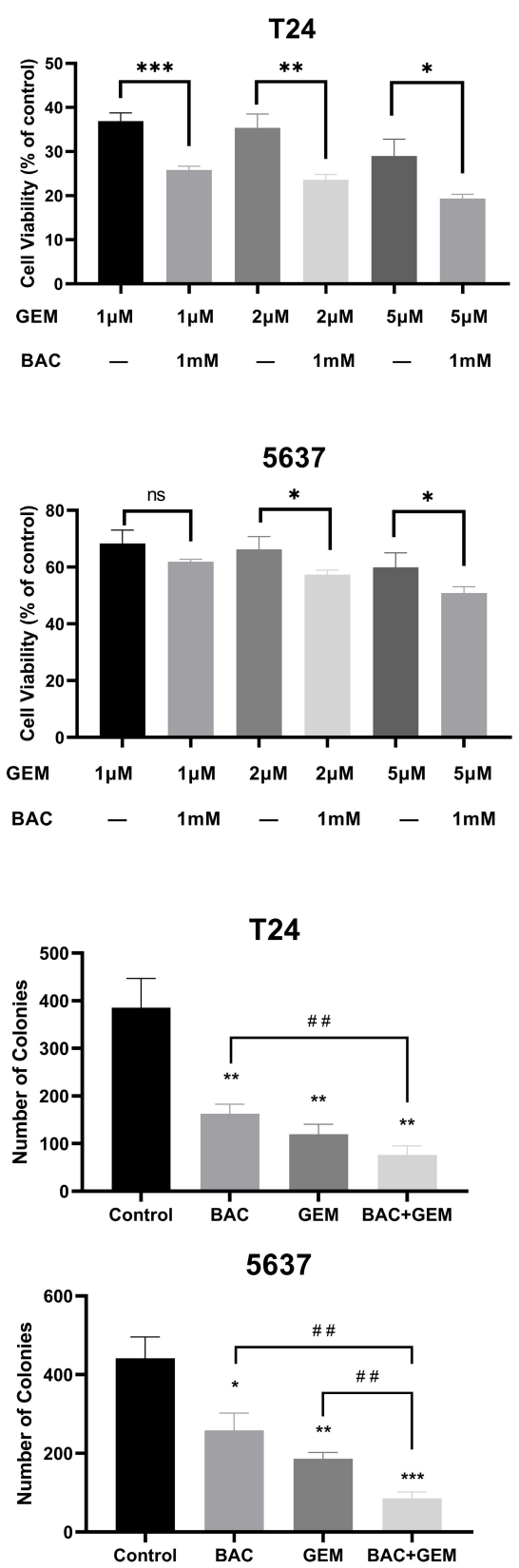

Figure 3 Effects of BAC and/or GEM treatment on the proliferation and colony formation ability of BC cells. (A) Viability of human BC T24 and 5637 cells after BAC treatment for $72 \mathrm{~h}$. ${ }^{* *} p<0.0 \mathrm{I}$; ${ }^{* *} p<0.00 \mathrm{I}$ and ${ }^{* * * *} p<0.000 \mathrm{I}$ vs control $(0 \mu \mathrm{M})$. (B) T24 and 5637 cells were treated with various concentrations of GEM. (C) T24 and 5637 cells were treated with BAC (I mM) and/or GEM (I, 2 and $5 \mu \mathrm{M})$. The cells were incubated for $72 \mathrm{~h}$ with BAC and $48 \mathrm{~h}$ with GEM. Then, the cell viability was determined with a Cell Counting Kit-8 assay. ns, $p>0.05 ;{ }^{*} p<0.05$; ${ }^{* *} p<0.01$ and $* * * p<0.001$. (D) Colony formation ability of T24 and 5637 cells was determined after treatment with BAC and/or GEM. ${ }^{*} p<0.05 ; * *<0.01$ and $* * * p<0.001$ vs control. ${ }^{*} p<0.01$ vs BAC and GEM combined group. Values are expressed as the mean \pm SD from three independent experiments. Statistical significance was analyzed by Student's $t$ test.

Abbreviations: GEM, gemcitabine; BAC, bacitracin.

with the control group in vitro. Functional assays revealed that proliferation and apoptosis in T24 and 5637 cells were significantly inhibited by BAC in a dose-dependent manner. Moreover, protein blotting demonstrated that $\mathrm{P} 4 \mathrm{HB}$ inhibition exerted a promoting effect on ERS and the apoptosis pathway. These results suggest that BAC may exert a slight antitumor effect that is related to ERS and apoptosis by inhibiting P4HB, 
A

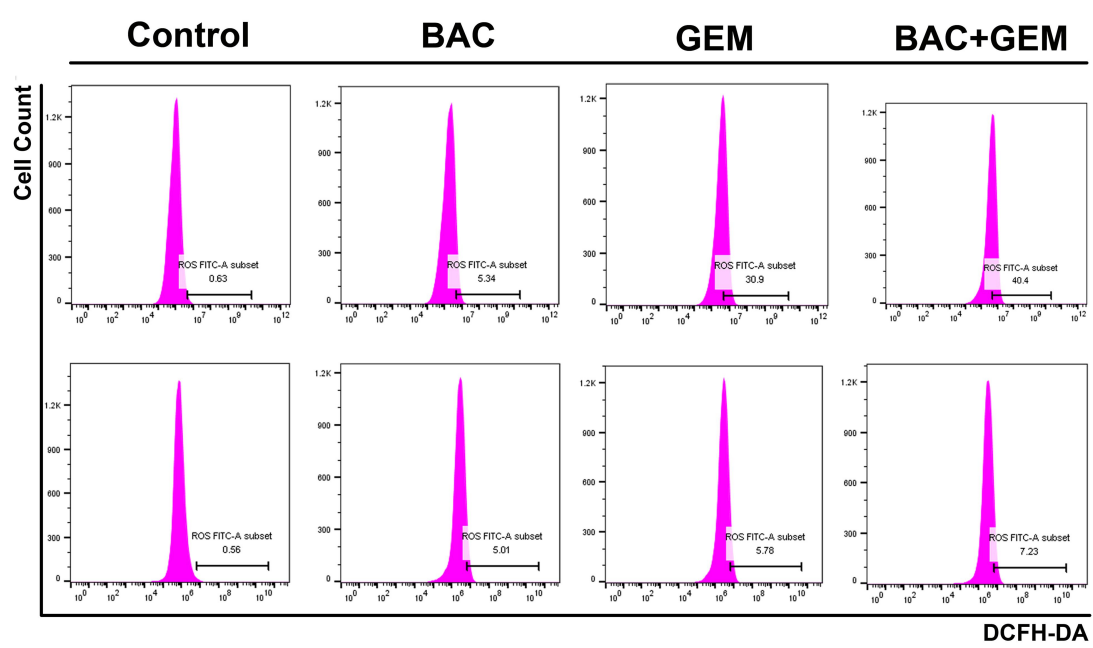

T24

T24

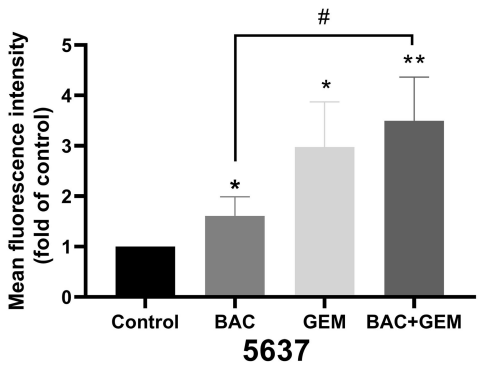

5637

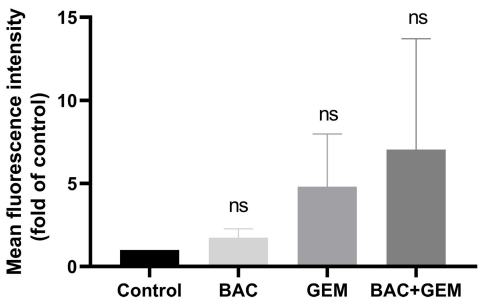

D
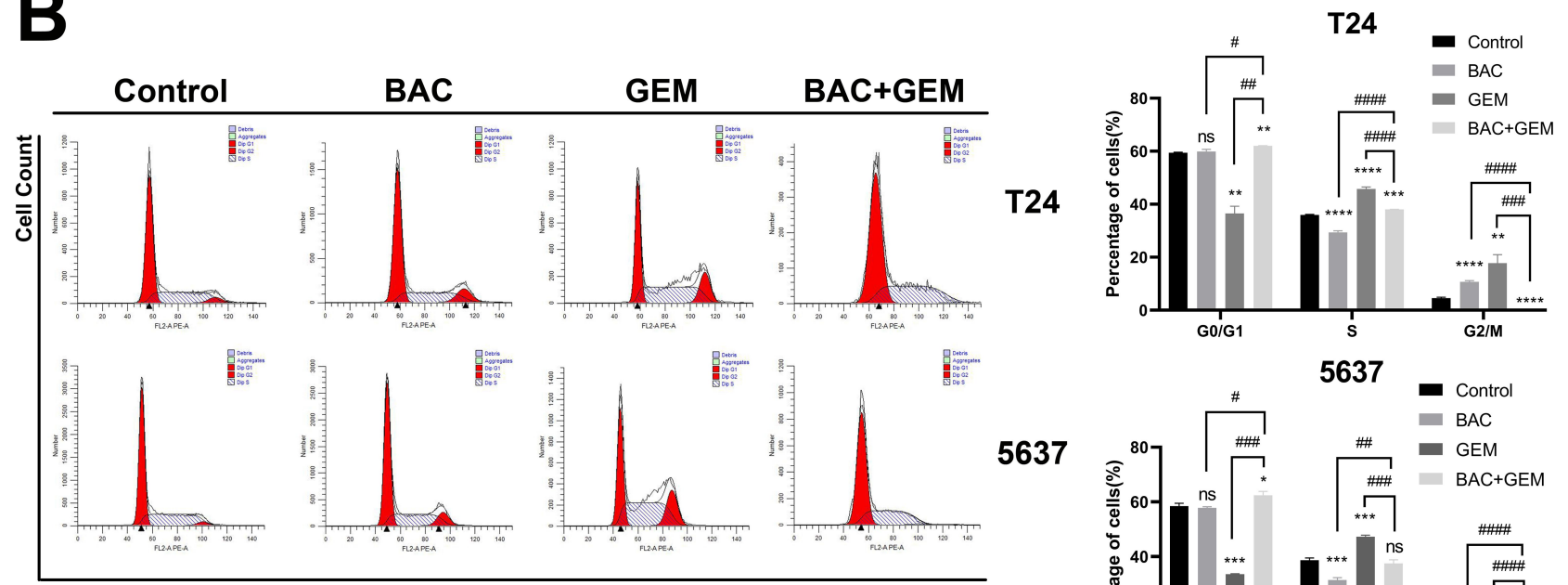

5637

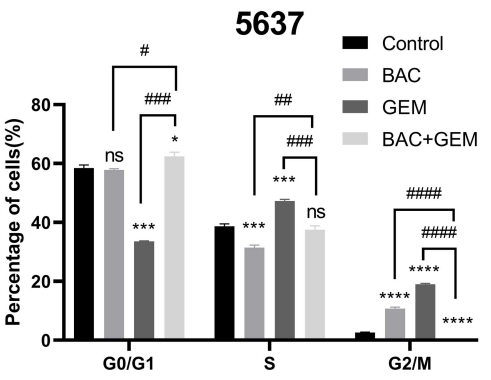

Figure 4 Effects of BAC and/or GEM treatment on the intracellular ROS generation and cell cycle in BC cells. T24 cells were treated with BAC (I mM) and/or GEM (200 $\mathrm{nM}) .5637$ cells were treated with BAC (I mM) and/or GEM (500 nM). (A) After $72 \mathrm{~h}$ of incubation following BAC treatment and $48 \mathrm{~h}$ of incubation following GEM treatment, the intracellular ROS content of T24 and 5637 cells was analyzed by flow cytometry. (B) After incubation, the cell cycle of T24 and 5637 cells was analyzed by flow cytometry. Values are expressed as the mean \pm SD from three independent experiments. ns, $p>0.05 ; * p<0.05 ; * * p<0.01 ; * * * p<0.001$ and $* * * * p<0.000$ I vs control.

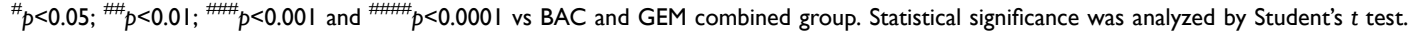

Abbreviations: GEM, gemcitabine; BAC, bacitracin.

but BAC alone does not induce an obvious antitumor effect in $\mathrm{BC}$.

A previous study indicated that inhibition of $\mathrm{P} 4 \mathrm{HB}$ by BAC combined with chemotherapeutic agents increased apoptosis in melanoma. ${ }^{31}$ The combination of $\mathrm{P} 4 \mathrm{HB}$ inhibition and radiotherapy had an enhanced antitumor effect on glioblastoma multiforme that occurred via a decrease in the capacity for DNA repair. ${ }^{9}$ P4HB inhibition exerted a synergistic effect on 3-bromopyruvate-induced antitumor efficacy in HCC in vivo. ${ }^{24}$

Phase I clinical trials confirmed that GEM had an overall response rate (ORR) of $27 \%$ in patients with metastatic BC, with milder adverse effects than other agents. ${ }^{32}$ The resistance of cancer cells to chemotherapy drugs often leads to chemotherapy failure. A study confirmed that the mechanism of the anticancer effect and 
A

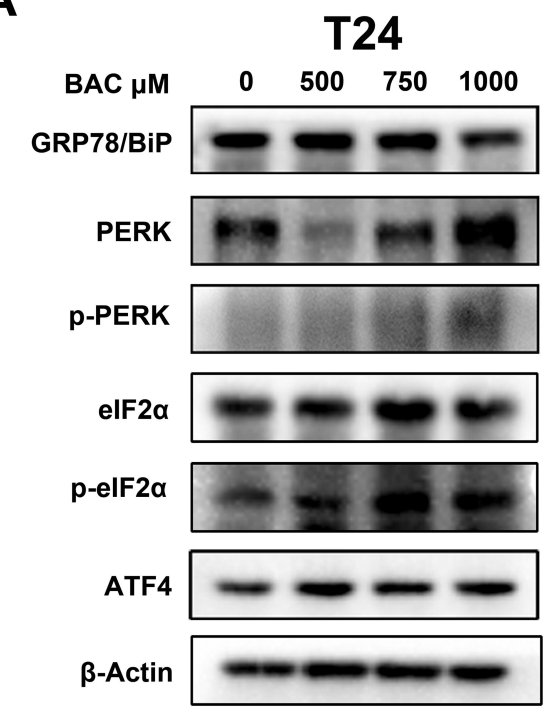

B

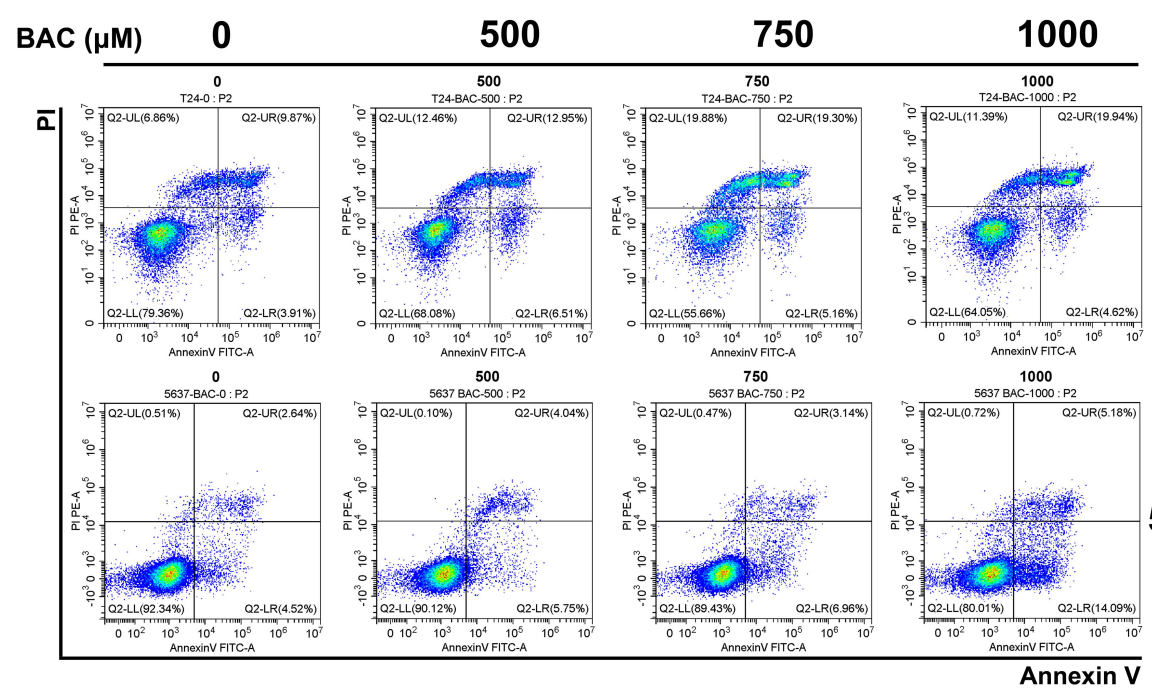

5637
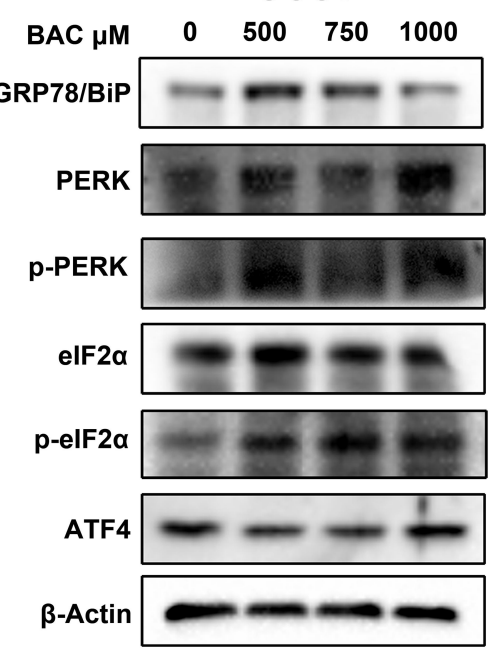

T24

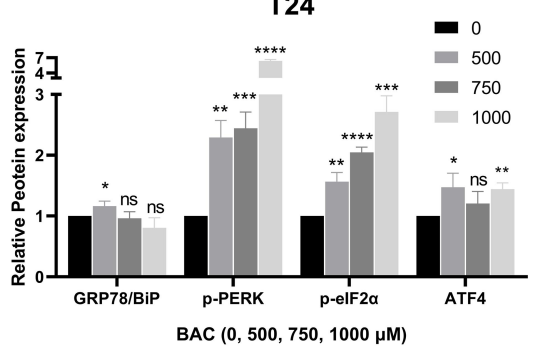

5637

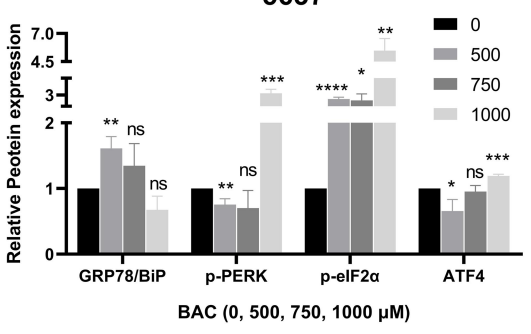

T24

T24

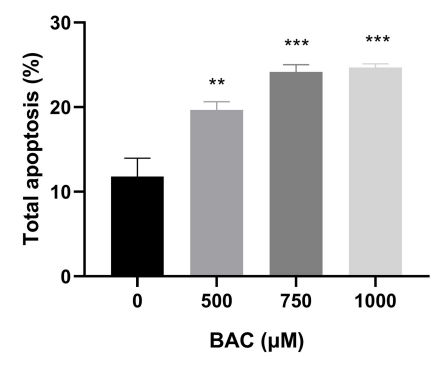

5637

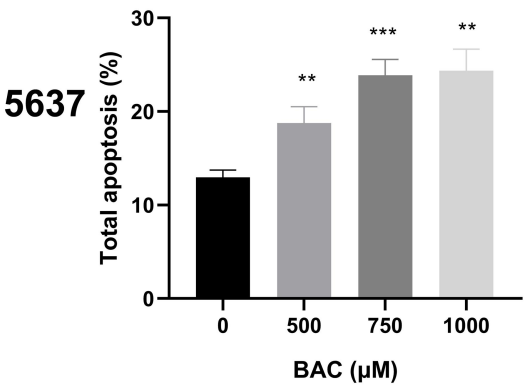

Figure 5 Effects of BAC treatment on ER stress and cell apoptosis in BC cells. T24 cells and 5637 cells were treated with BAC (0, $250,750,1000 \mu M)$. (A) After 72 h of incubation with BAC treatment, the expression of ER stress pathway proteins in T24 and 5637 cells was analyzed by Western blot analysis. (B) After incubation, the apoptotic cell proportion of T24 and 5637 cells was analyzed by flow cytometry. Values are expressed as the mean \pm SD from three independent experiments. ns, $p>0.05$; $* p<0.05$; $* *<0.01 ; * * *<0.001$ and $* * * *<0.0001$ vs control. Statistical significance was analyzed by Student's $t$ test.

Abbreviations: GEM, gemcitabine; BAC, bacitracin.

resistance of GEM is related to ERS. ${ }^{33}$ In the present study, we aimed to investigate whether targeted inhibition of $\mathrm{P} 4 \mathrm{HB}$ and GEM has a synergistic effect on BC. Pretreatment with BAC enhanced the decrease in cell proliferation and colony formation and the increase in cellular apoptosis and ROS contents and augmented G0/ G1 arrest induced by GEM in T24 and 5637 cells. The results demonstrated that $\mathrm{BAC}$ augments the antitumor efficacy of GEM in BC cells through an ERS-mediated apoptotic pathway. Western blot analysis of cell apoptosisassociated protein revealed that the levels of C-caspase-3 and C-PARP increased the most in the combination drug group. Detection of PERK/eIF2 $\alpha /$ ATF4/CHOP pathway proteins validated the assumption that $\mathrm{BAC}$ enhances the antitumor efficacy of GEM in BC. BAC is a nephrotoxic drug, so the development of a low-molecular-weight P4HB inhibitor with low nephrotoxicity may provide a new solution for the systemic treatment of 

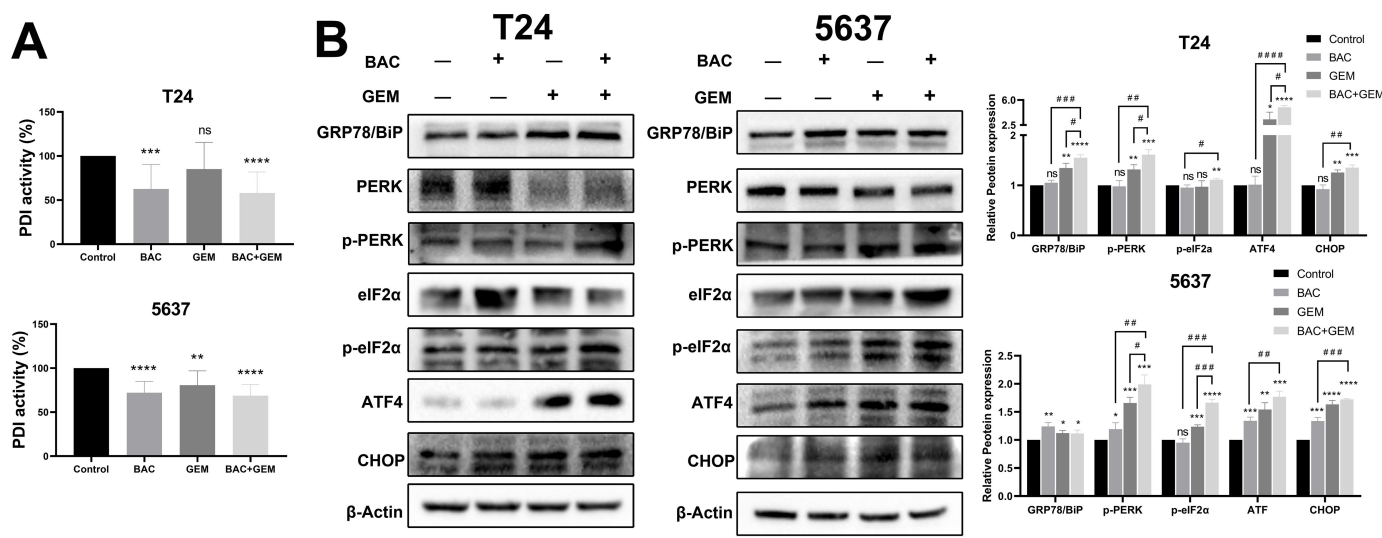

C

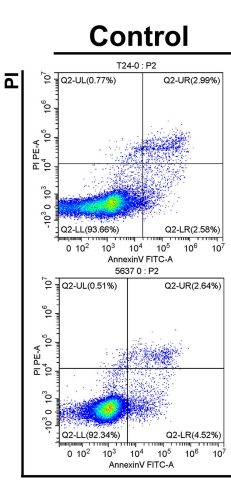

BAC

GEM BAC+GEM
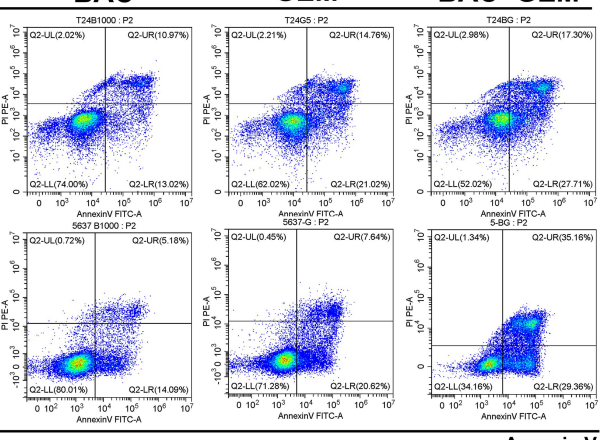

T24
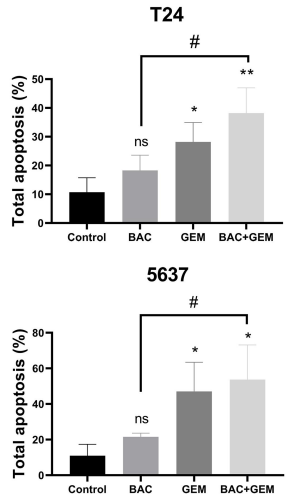

T24

D
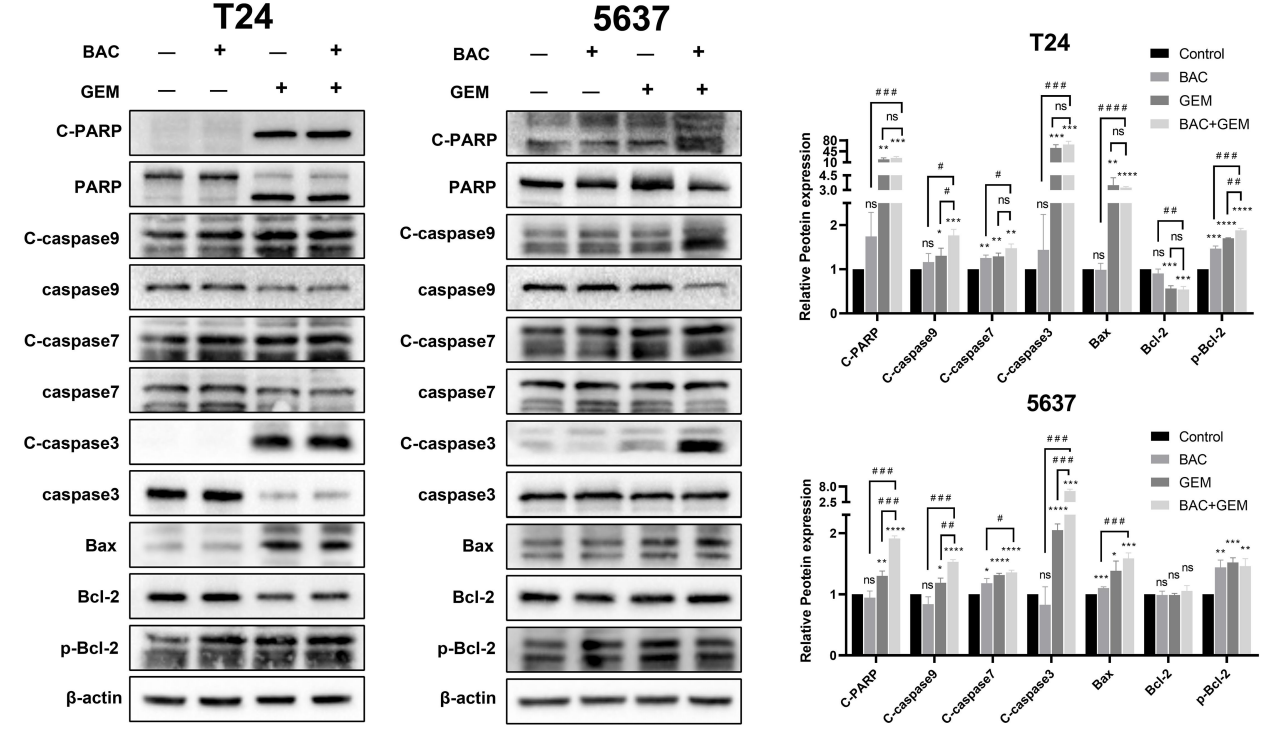

Figure 6 Effects of BAC and/or GEM treatment on the intracellular ROS generation and cell cycle in BC cells. T24 cells were treated with BAC (I mM) and/or GEM (200 nM). 5637 cells were treated with BAC (I mM) and/or GEM (500 nM). T24 and 5637 cells were treated with BAC for 72 h and GEM for 48 h. (A) PDI activity was determined in both T24 and 5637 cells. (B) After treatment, the expression of ER stress pathway proteins in T24 and 5637 cells was analyzed by Western blot analysis. (C) After incubation, the apoptotic cell proportions of T24 and 5637 cells were analyzed by flow cytometry. (D) Apoptotic pathway proteins were analyzed by Western blot analysis. $\beta$-actin served as a loading control. Values are expressed as the mean \pm SD from three independent experiments. ns, $p>0.05 ; * p<0.05 ; * * p<0.01 ; * * * p<0.001$ and

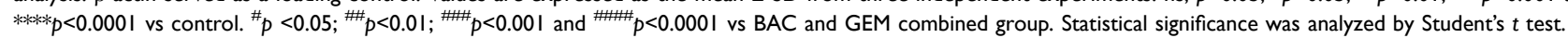

Abbreviations: GEM, gemcitabine; BAC, bacitracin; PDI, protein disulfide isomerase.

metastatic $\mathrm{BC}$ in the future. Intravesical instillation of GEM in patients with low-grade NMBC has recently been successfully tested to reduce disease recurrence over a median of 4.0 years. ${ }^{34}$ Accordingly, BAC or novel low-molecular-weight P4HB inhibitors may become an option for intravesical instillation alone or combined with GEM. However, this finding should be explored in future investigations. 


\section{Conclusion}

In conclusion, our data demonstrate that $\mathrm{P} 4 \mathrm{HB}$ is highly expressed in $\mathrm{BC}$ tissues compared with adjacent normal tissues and that high mRNA and protein levels of P4HB are significantly associated with poor prognosis in $\mathrm{BC}$ patients. To our knowledge, this is the first study to indicate that $\mathrm{P} 4 \mathrm{HB}$ is correlated with the clinicopathological features and prognosis of $\mathrm{BC}$ patients. Targeted $\mathrm{P} 4 \mathrm{HB}$ inhibition by BAC suppressed cell viability, increased cell apoptosis, and activated ERS and apoptotic pathways in highly P4HBexpressed BC cells in vitro. Furthermore, inhibition of P4HB enhanced GEM-induced antitumor effects by activating the PERK/eIF2 $\alpha /$ ATF4/CHOP pathway in highly P4HB-expressed BC cells. The present research may provide a biomarker that can predict the prognosis of $\mathrm{BC}$ patients and a therapeutic target that can be incorporated into new treatment strategies for $\mathrm{BC}$ in the future.

\section{Acknowledgments}

The authors sincerely thank Yan Wang, Di Wang, Hongying Chen and Sisi $\mathrm{Wu}$ for their excellent support of IHC and cell biology techniques.

\section{Funding}

This work was supported by grants from the 1.3.5 project for disciplines of excellence, West China Hospital, Sichuan University (ZY2016104), and Pillar Program from the Department of Science and Technology of Sichuan Province (2018SZ0219).

\section{Disclosure}

The authors report no other potential conflicts of interest related to this work.

\section{References}

1. Siegel RL, Miller KD, Jemal A. Cancer statistics, 2020. CA Cancer J Clin. 2020;70(1):7-30. doi:10.3322/caac.21590

2. Chen W, Zheng R, Baade PD, et al. Cancer statistics in China, 2015. CA Cancer J Clin. 2016;66(2):115-132. doi:10.3322/caac.21338

3. Felsenstein KM, Theodorescu D. Precision medicine for urothelial bladder cancer: update on tumour genomics and immunotherapy. Nat Rev Urol. 2018;15(2):2. doi:10.1038/nrurol.2017.179

4. Schlack K, Boegemann M, Steinestel J, Schrader AJ, Krabbe L-M. The safety and efficacy of gemcitabine for the treatment of bladder cancer. Expert Rev Anticancer Ther. 2016;16(3):255-271. doi:10.1586/ 14737140.2016.1143777

5. Balar AV, Apolo AB, Ostrovnaya I, et al. Phase II study of gemcitabine, carboplatin, and bevacizumab in patients with advanced unresectable or metastatic urothelial cancer. J Clin Oncol. 2013;31 (6):724-730. doi:10.1200/JCO.2012.42.5215
6. Krege S, Rexer H, Vom Dorp F, et al. Prospective randomized double-blind multicentre phase II study comparing gemcitabine and cisplatin plus sorafenib chemotherapy with gemcitabine and cisplatin plus placebo in locally advanced and/or metastasized urothelial cancer: SUSE (AUO-AB 31/05). BJU Int. 2014;113(3):429-436. doi:10.1111/bju.12437

7. Wang M, Kaufman RJ. The impact of the endoplasmic reticulum protein-folding environment on cancer development. Nat Rev Cancer. 2014;14(9):581-597. doi:10.1038/nrc3800

8. Vanacker H, Vetters J, Moudombi L, Caux C, Janssens S, Michallet M-C. Emerging role of the unfolded protein response in tumor immunosurveillance. Trends Cancer. 2017;3(7):491-505. doi:10.1016/j.trecan.2017.05.005

9. Liu Y, Ji W, Shergalis A, et al. Activation of the unfolded protein response via inhibition of protein disulfide isomerase decreases the capacity for DNA repair to sensitize glioblastoma to radiotherapy. Cancer Res. 2019;79(11):2923-2932. doi:10.1158/0008-5472.CAN18-2540

10. Cheng HP, Liu Q, Li Y, Li XD, Zhu CY. The inhibitory effect of PDIA6 downregulation on bladder cancer cell proliferation and invasion. Oncol Res. 2017;25(4):587-593. doi:10.3727/ 096504016X14761811155298

11. Safwat El-Deeb O, Abd-Ellatif RN, Othman TS, Afifi M, El-Magd $\mathrm{M}$. The evolving role of protein disulfide isomerase A3 in Egyptian bladder cancer patients. Gene. 2019;693:76-83. doi:10.1016/j. gene.2019.01.024

12. Noiva R. Protein disulfide isomerase: the multifunctional redox chaperone of the endoplasmic reticulum. Semin Cell Dev Biol. 1999;10 (5):481-493. doi:10.1006/scdb.1999.0319

13. Xu S, Sankar S, Neamati N. Protein disulfide isomerase: a promising target for cancer therapy. Drug Discov Today. 2014;19(3):222-240. doi:10.1016/j.drudis.2013.10.017

14. Zhu Z, He A, Lv T, Xu C, Lin L, Lin J. Overexpression of P4HB is correlated with poor prognosis in human clear cell renal cell carcinoma. Cancer Biomark. 2019;26(4):431-439. doi:10.3233/ CBM-190450

15. Xia W, Zhuang J, Wang G, Ni J, Wang J, Ye Y. P4HB promotes HCC tumorigenesis through downregulation of GRP78 and subsequent upregulation of epithelial-to-mesenchymal transition. Oncotarget. 2017;8(5):8512-8521. doi:10.18632/oncotarget.14337

16. Sun S, Lee D, Ho AS, et al. Inhibition of prolyl 4-hydroxylase, beta polypeptide (P4HB) attenuates temozolomide resistance in malignant glioma via the endoplasmic reticulum stress response (ERSR) pathways. Neuro Oncol. 2013;15(5):562-577. doi:10.1093/neuonc/ not005

17. Mootha VK, Lindgren CM, Eriksson K-F, et al. PGC-1alpharesponsive genes involved in oxidative phosphorylation are coordinately downregulated in human diabetes. Nat Genet. 2003;34 (3):267-273. doi:10.1038/ng 1180

18. Subramanian A, Tamayo P, Mootha VK, et al. Gene set enrichment analysis: a knowledge-based approach for interpreting genome-wide expression profiles. Proc Natl Acad Sci U S A. 2005;102 (43):15545-15550. doi:10.1073/pnas.0506580102

19. Wang X, Yang Y, Li J, Bai Y, Tang Y, Han P. Effects of fine particulate matter on erectile function and its potential mechanism in rats. Urology. 2017;102(265):e269-265. doi:10.1016/j. urology.2016.08.034

20. Zhang J, Wu Y, Lin Y-H, et al. Prognostic value of hypoxia-inducible factor-1 alpha and prolyl 4-hydroxylase beta polypeptide overexpression in gastric cancer. World $J$ Gastroenterol. 2018;24 (22):2381-2391. doi:10.3748/wjg.v24.i22.2381

21. Zhou Y, Yang J, Zhang Q, et al. P4HB knockdown induces human HT29 colon cancer cell apoptosis through the generation of reactive oxygen species and inactivation of STAT3 signaling. Mol Med Rep. 2019;19(1):231-237. doi:10.3892/mmr.2018.9660 
22. Peng Z, Chen $\mathrm{Y}$, Cao $\mathrm{H}$, et al. Protein disulfide isomerases are promising targets for predicting the survival and tumor progression in glioma patients. Aging (Albany NY). 2020;12(3):2347. doi:10.18632/aging.102748

23. Zou H, Wen C, Peng Z, et al. P4HB and PDIA3 are associated with tumor progression and therapeutic outcome of diffuse gliomas. Oncol Rep. 2018;39(2):501-510. doi:10.3892/or.2017.6134

24. Yu SJ, Yoon J-H, Yang J-I, et al. Enhancement of hexokinase II inhibitor-induced apoptosis in hepatocellular carcinoma cells via augmenting ER stress and anti-angiogenesis by protein disulfide isomerase inhibition. J Bioenerg Biomembr. 2012;44(1):101-115. doi:10.1007/s10863-012-9416-5

25. Sun S, Kiang KMY, Ho ASW, et al. Endoplasmic reticulum chaperone prolyl 4-hydroxylase, beta polypeptide (P4HB) promotes malignant phenotypes in glioma via MAPK signaling. Oncotarget. 2017;8 (42):71911-71923. doi:10.18632/oncotarget.18026

26. Moon HW, Han HG, Jeon YJ. Protein quality control in the endoplasmic reticulum and cancer. Int J Mol Sci. 2018;19(10):10. doi:10.3390/ijms 19103020

27. Szegezdi E, Logue SE, Gorman AM, Samali A. Mediators of endoplasmic reticulum stress-induced apoptosis. EMBO Rep. 2006;7 (9):880-885. doi:10.1038/sj.embor.7400779

28. Pan M-Y, Shen Y-C, Lu C-H, et al. Prodigiosin activates endoplasmic reticulum stress cell death pathway in human breast carcinoma cell lines. Toxicol Appl Pharmacol. 2012;265(3):325-334. doi:10.1016/j. taap.2012.08.034
29. Hedgepeth SC, Garcia MI, Wagner LE, et al. The BRCA1 tumor suppressor binds to inositol 1,4,5-trisphosphate receptors to stimulate apoptotic calcium release. J Biol Chem. 2015;290(11):7304-7313. doi:10.1074/jbc.M114.611186

30. Ming L-J, Epperson JD. Metal binding and structure-activity relationship of the metalloantibiotic peptide bacitracin. J Inorg Biochem. 2002;91(1):46-58. doi:10.1016/S0162-0134(02)00464-6

31. Lovat PE, Corazzari M, Armstrong JL, et al. Increasing melanoma cell death using inhibitors of protein disulfide isomerases to abrogate survival responses to endoplasmic reticulum stress. Cancer Res. 2008;68(13):5363-5369. doi:10.1158/0008-5472.CAN-08-0035

32. Pollera CF, Ceribelli A, Crecco M, Calabresi F. Weekly gemcitabine in advanced bladder cancer: a preliminary report from a phase I study. Ann Oncol. 1994;5(2):182-184. doi:10.1093/oxfordjournals. annonc.a058775

33. Bahar E, Kim J-Y, Yoon H. Chemotherapy resistance explained through endoplasmic reticulum stress-dependent signaling. Cancers (Basel). 2019;11(3):3. doi:10.3390/cancers 11030338

34. Messing EM, Tangen CM, Lerner SP, et al. Effect of intravesical instillation of gemcitabine vs saline immediately following resection of suspected low-grade Non-Muscle-Invasive bladder cancer on tumor recurrence: SWOG S0337 Randomized Clinical Trial. JAMA. 2018;319(18):1880-1888. doi:10.1001/jama.2018.4657

\section{Publish your work in this journal}

OncoTargets and Therapy is an international, peer-reviewed, open access journal focusing on the pathological basis of all cancers, potential targets for therapy and treatment protocols employed to improve the management of cancer patients. The journal also focuses on the impact of management programs and new therapeutic agents and protocols on patient perspectives such as quality of life, adherence and satisfaction. The manuscript management system is completely online and includes a very quick and fair peer-review system, which is all easy to use. Visit http://www.dovepress.com/ testimonials.php to read real quotes from published authors. 